\title{
Nuevas dinámicas de la regionalización universitaria en América Latina
}

New Dynamics of the Higher Education Regionalization in Latin America

Nouvelles dynamiques de la régionalisation universitaire en Amérique latine

Novas dinâmicas da regionalização universitária na América Latina

Fecha de recepción: 10 DE MAYO DE 2014/Fecha de aceptación: 30 DE NOVIEMBRE DE 2015/Fecha de disponibilidad en línea: 15 DE MARZO DE 2016

Encuentre este artículo en http://magisinvestigacioneducacion.javeriana.edu.co/

Escrito por CLAUDIO RAMA UnIVERSIDAD DE LA EMPRESA, UDE Consejo de EduCACIÓN SUPERIOR, CES MONTEVIDEO, URUGuAY claudiorama@gmail.com

Marcelo Cevallos Consejo de Educación Superior, CES QUITO, ECUADOR

La desigualdad regional en el acceso, el egreso, la equidad y marcelo.cevallos@ces.gob.ec la calidad es una de las características históricas de la educación superior en América Latina asociada al carácter inicial de elite del servicio universitario y las formas que asume la desigualdad estructural de la región. Sin embargo, tal realidad está cambiando por medio de una masificación que reduce las desigualdades regionales universitarias con diversidad de modalidades. El presente artículo es una reflexión derivada de una investigación comparativa regional más amplia sobre los cambios en los procesos de regionalización, y que muestra la mayor propensión hacia formas de descentralización (nuevas instituciones y diversidad de mecanismos) frente a las formas tradicionales de desconcentración (sedes, subsedes o filiales) que caracterizaron la regionalización de la educación superior en el continente. Ella devela una diversidad de mecanismos de oferta regional de servicios de educación superior, fundamentalmente públicos pero también privados, que son al tiempo los que han sostenido en los últimos años la expansión de la matrícula y el aumento de la cobertura.

\section{Palabras clave}

Pertinencia; América Latina; poder; educación superior; diferenciación; calidad; matrícula; regionalización

\section{Transferencia a la práctica}

La presente investigación sustenta los enfoques que ven las desigualdades regionales como parte de la debilidad de los sistemas de educción en términos de cobertura y calidad. Valoriza la necesidad de incluir una mayor pertinencia en los procesos de enseñanza, con una mayor valorización de la territorialidad en las prácticas pedagógicas y en las políticas educativas. Muestra la ausencia de un modelo rígido de regionalización y sugiere la construcción de enfoques regionales específicos en los currículos, las prácticas educativas y las articulaciones laborales del proceso de enseñanza, en correlación con el modelo específico de institución y con el modelo educativo.

Para citar este artículo / To cite this article / Pour citer cet article / Para citar este artigo

Rama, C. \& Cevallos, M. (2016). Nuevas dinámicas de la regionalización universitaria en América Latina. magis, Revista Internacional de Investigación en Educación, 8 (17), 99-134. http://dx.doi.org/10.11144/Javeriana.m8-17.ndru 


\section{Key words}

Relevance; regionalization; Latin America; empowerment higher education; institutional differentiation; quality; coverage massification

\section{Abstract}

Regional inequality regarding access, graduation, equity and quality is one of the historical characteristics of higher education in Latin America. This inequality is associated with the initial character of the elite university service and the ways structural inequality in the region has been assumed. However, this reality is changing due to a process of massification that reduces university regional inequalities with diverse modalities. This article is a reflection derived from a broader regional comparative research that studies the changes within the processes of regionalization. Also, it shows the greater tendency toward forms of decentralization (new institutions and different mechanisms) over traditional forms of decentralization (offices, sub-offices or subsidiaries) that characterized the regionalization of higher education in the continent. This research reveals various mechanisms of regional higher education services, mainly public but also private, which are also those who have supported over the years the expansion of enrollment and have increased coverage.

\section{Transfer to practice}

This research supports the approaches that consider regional inequalities as part of the weaknesses of education systems regarding coverage and quality. This paper argues that it is necessary to put greater relevance in teaching processes, considering a higher valuation of territoriality in pedagogical practices and educational policies. This paper argues that there is an absence of a rigid model of regionalization, thus, it suggests to create specific regional approaches in curricula and teaching practices according to the specific pedagogical model of the institution and the educational system.

\section{Mots clés}

pertinence; régionalisation; Amérique Latine; capacité d'agir; éducation supérieure; différentiation institutionnelle: qualité; massification de la couverture

\section{Résumé}

L'inégalité régionale dans l'accès, l'obtention du diplôme, l'égalité et la qualité est une des caractéristiques historiques de l'éducation supérieure en Amérique Latine associée au caractère initial de l'élite du service universitaire et les formes dont se prend l'inégalité structurelle dans la région. Néanmoins, telle réalité est en train de changer au moyen d'une massification qui réduit les inégalités régionales universitaires avec une diversité de modalités. Cet article est une réflexion qui découle d'une recherche comparative régionale plus ample sur les changements dans les processus de régionalisation, dont on montre la plus grande tendance envers les formes du décentrement (nouvelles institutions et diversité de mécanismes) en face des formes traditionnelles de décentrement (sièges, sièges connexes, ou filiales) qui caractérisent la régionalisation de l'éducation supérieure dans le continent. La recherche montre une diversité de mécanismes d'offre régionale de services d'éducation supérieure, notamment publics mais aussi privés, qui ont soutenu dans les dernières années l'expansion de l'inscription et l'augmentation de la couverture.

\section{Transfert à la pratique}

Cette recherche prend les perspectives qui voient les inégalités régionales en tant qu'une partie de la faiblesse des systèmes d'éducation en termes de couverture et qualité. On apprécie le besoin d'inclure une plus grande pertinence dans les processus d'enseignement, avec une plus grande estimation du contexte territorial dans les pratiques pédagogiques et dans les politiques éducatives. On montre l'absence d'un modèle droit de régionalisation et on suggère la construction de perspectives régionales dans les curriculums, les pratiques éducatives et les articulations au travail du processus d'enseignement, par rapport au modèle spécifique de l'institution et avec le modèle éducatif.

\section{Palavras-chave Pertinência; regionalização; América Latina; empoderamento; educação superior; diferenciação institucional; qualidade; massificação da cobertura}

\section{Palavras-chave descritor}

A desigualdade regional no acesso, na graduação, na equidade e na qualidade é uma das características históricas da educação superior na América Latina associada ao caráter inicial de elite do serviço universitário e das formas que assume a desigualdade estrutural da região. No entanto, tal realidade está mudando por meio de uma massificação que reduz as desigualdades regionais universitárias com diversidade de modalidades. O presente artigo é uma reflexão derivada de uma pesquisa comparativa regional mais ampla sobre as mudanças nos processos de regionalização, e que mostra a maior propensão para formas de descentralização (novas instituições e diversidade de mecanismos) frente às formas tradicionais de desconcentração (sedes, subsedes ou filiais) que caracterizaram a regionalização da educação superior no continente. Revela-se uma diversidade de mecanismos de oferta regional de serviços de educação superior, fundamentalmente públicos mas também privados, que são ao mesmo tempo os que têm sustentado nos últimos anos a expansão da matrícula e o aumento da cobertura.

\section{Transferência à prática}

A presente pesquisa sustenta os enfoques que veem as desigualdades regionais como parte da debilidade dos sistemas de educação em termos de cobertura e qualidade. Valoriza a necessidade de incluir uma maior pertinência nos processos de ensino, com uma maior valorização da territorialidade nas práticas pedagógicas e nas políticas educativas. Mostra a ausência de um modelo rígido de regionalização e sugere a construção de enfoques regionais específicos nos currículos, nas práticas educativas e nas articulações laborais do processo de ensino, em correlação com o modelo específico de instituição e com o modelo educativo. 


\section{Introducción}

El presente artículo de investigación comparativa a escala de América Latina analiza el cambio en las dinámicas de la regionalización de la educación superior en las últimas décadas y la irrupción de una diversidad de modelos de regionalización que están impulsando la expansión de la cobertura. El objetivo del trabajo se enmarca en la identificación de la existencia de cambios en las modalidades y formas que está asumiendo la regionalización en el contexto de lo que se ha dado en llamar la tercera reforma de la educación superior (Rama, 2006). El estudio se basó en un análisis de las nuevas instituciones de educación superior, fundamentalmente las públicas, como parte de procesos de diferenciación institucional, para develar las características específicas de la cobertura regional. Ello identificó una amplia tipología de expresiones — cada una con un componente particular de regionalización-, que verifican la hipótesis de la existencia de un cambio en los procesos de regionalización y una transición desde modelos basados en procesos de desconcentración a partir de sedes como forma de expansión de las instituciones en los territorios hacia formas descentralizadas con diversidad de modelos de regionalización universitaria y que aportan nuevas formas de ampliación de la cobertura de forma sistemática en los países.

En tal contexto, incluso se identificó la existencia de dinámicas de desregionalización, con el paso de una educación a distancia tradicional basada en centros de apoyo, a una nueva educación virtual sin estos niveles de empoderamiento. La investigación se concentró en los países de habla hispana y se focalizó en el análisis de seis países (Argentina, Brasil, México, Perú, Paraguay y Venezuela), que manifiestan una intensidad dinámica de regionalización. Sin embargo, al tiempo, se relevaron adicionalmente ejemplos y casos en Ecuador, Bolivia, Colombia y Uruguay para aportar una visión regional, que permitieron identificar más claramente la existencia de nuevas modalidades y tipologías de regionalización.

A partir de una amplia revisión regional comparativa, la investigación identificó la mayor propensión hacia formas de descentralización (nuevas instituciones) y su asociación con distintos mecanismos de acceso y de prestación de servicios terciarios, como ejes de soporte a los procesos de cobertura y su contribución al cambio en las formas tradicionales de la desigualdad de la educación superior desde el punto de vista espacial. En la década pasada, el crecimiento de la matrícula y de la cobertura fue muy elevado; en parte, sobre este incremento descansan los procesos de regionalización que se analizarán. La cobertura de la educación superior en América Latina y el Caribe pasó de 23,4\% en el año 2000 a 41\% en 2010, al pasar de 11,269 millones de estudiantes a 21,160 en el mismo período con un incremento de $6,64 \%$ interanual. El incremento en el primer quinquenio (2000-2005) de la tasa de cobertura fue de 35,8\% mientras que en el segundo (2005-2010) el aumento fue de $29 \%$. En términos absolutos, el incremento en el primer quinquenio fue de $41,4 \%$ y en el segundo, 35,5\% (UNESCO/UIS). Estos incrementos de matrícula se apoyan en los cambios en la regionalización.

Tales dinámicas sistémicas y diferenciadas en la década pasada contrastan con las tradicionales formas de desconcentración (sedes, subsedes o filiales) que han caracterizado la regionalización y la expansión dominante de las instituciones universitarias en América Latina.

La investigación apuntó a identificar las formas específicas de diferenciación en términos de regionalización universitaria, que están conformando nuevas tipologías institucionales universitarias. Por último, el
Descripción del artículo | Article description | Description de l'article | Artigo descrição

En este artículo de reflexión, a partir de su recorrido como investigadores en la materia, los autores abordan en primer lugar las transformaciones de las formas educativas a partir de las dinámicas de masificación. Esta es un área poco abordaba en la investigación y es parte del recorrido investigativo de los autores para ir analizando los diversos ámbitos en los cuales se conforma la complejidad de los sistemas universitarios en sus procesos de transformaciones. La línea de investigación de los autores - transformaciones de los sistemas universitarios en América Latina - ha derivado en esta reflexión, que contribuye a complejizar los procesos en cursos y develar algunos componentes de las dinámicas de superación de las desigualdades universitarias en la región y formular tipologías que permiten un abordaje más amplio pues develan las complejidades de la regionalización universitaria. El presente trabajo fue patrocinado por el Proyecto Prometeo de la Secretaría de Educación Superior, Ciencia, Tecnología e Innovación de la República del Ecuador. 
trabajo sostiene algunas líneas de reflexión e hipótesis futuras de investigación sobre la asociación entre las formas de regionalización, en términos de empoderamiento y de pertinencia, y los niveles de calidad de las ofertas de la educación superior en los países.

\section{La tradicional inequidad regional universitaria}

En América Latina, la inequidad regional entre las capitales o las grandes ciudades y el interior ha sido uno de los componentes que han caracterizado la educación superior desde sus inicios. Esta dinámica en los aspectos de educación superior ha sido escasamente analizada en la región (Herrera, 2013; Martínez, 2002) e incluso ha sido soslayada en algunos buenos estudios sobre la desigualdad que dan más atención a la problemática social que a la espacial (CINDA, 2010; Ezcurra, 2011; Solana, 2005). En tal sentido, los estudios de las desigualdades universitarias se han centrado en los circuitos desiguales de calidad, de género (IESALC, 2005) y de la condición socioeconómica de los estudiantes, o en estudios sobre políticas de compensación (Bolaños, Tattay \& Pancho, 2006; Mato, 2015; Pedroza-Flórez, Villalobos-Monroy, Farfán-García \& NavarreteSánchez, 2010).

La dimensión de la desigualdad regional es una expresión de las desigualdades educativas y se refiere a las diferencias en la educación ofrecida y demandada entre las diversas áreas geográficas, entre el medio rural y el medio urbano, entre las grandes ciudades, las capitales departamentales y las ciudades menores en términos de indicadores de calidad, de cantidad, de diversidad y de pertinencia. Estas diferencias regionales constituyen uno de los ejes de las desigualdades socioeconómicas pues impactan en el desarrollo económico de las regiones al dotarlas de menos capital humano en términos de cantidad y de competencias y, por ende, de oportunidades para las personas y para las inversiones. Las características de la dotación del capital humano en las regiones son determinantes de sus procesos productivos y de los niveles de valor agregado y productividad.

En la mayor parte de América Latina, el sistema educativo ha sido la expresión - y a la vez ha retroalimentado- un modelo socioeconómico con un alto sesgo macrocefálico y con desigualdades de acceso, cobertura y egreso en las regiones del interior de los países. También ha sido expresión de la escasa pertinencia local y de la poca calidad de los programas localizados en la mayoría de las subsedes o filiales respecto a los ofrecidos en las capitales por esas mismas universidades. Incluso también ha habido diferencias entre las universidades asociadas a su localización geográfica sobre la base de una diferencia de los aportes presupuestales públicos por alumnos. Todo ello ha reforzado las dinámicas socioeconómicas espacialmente desiguales. Durante décadas, la alta concentración de la matrícula de las universidades públicas en las capitales de los países determinó accesos mínimos y de elite en las regiones, y solo los sectores de altos ingresos del interior pudieron asumir los altos costos de traslado de sus hijos estudiantes. En las capitales, las múltiples residencias estudiantiles universitarias privadas o públicas de los gobiernos regionales eran una expresión de estos desequilibrios. Muchos de los estudiantes que se trasladaban no regresaban a sus ciudades de origen y constituían uno de los mecanismos del drenaje de recursos humanos de las regiones. Esto propició que, durante décadas, en el interior de los países, la localización centralizada de la educación cumpliera el rol de facilitar la reproducción de las estructuras desiguales de ingreso (Carnoy, 2007; San Segundo, 2001; Villa, 2001). 
La universidad latinoamericana nació como una institución de elite y pervivió hasta fines del siglo $X X$, dominantemente como una universidad urbana, de hombres y de estudiantes de altos recursos. Recién desde los 70 , se ha ido democratizando mediante la masificación de la cobertura (Brunner, 1990; García-Guadilla, 2004; Rama, 2009b), y mediante una diferenciación institucional que al tiempo ha implicado una relativa regionalización con lo cual han ido reduciéndose las anteriores desigualdades espaciales. Sin esa relativa regionalización, la cobertura universitaria de elite no hubiera aumentado en la dimensión en que ocurrió. Sin embargo, esta regionalización no ha sido meramente resultado de la expansión del sistema universitario, sino que ella derivó de dinámicas asociadas a la democratización política, a nuevas demandas de acceso, a un aumento de los egresados de educación media, a nuevas concepciones asociadas a la descentralización y a una expansión de las economías regionales que requieren recursos humanos altamente capacitados para su desarrollo. También ha influenciado la propia dinámica competitiva entre las instituciones educativas que buscan aumentar sus coberturas y sus escalas. Todas estas dinámicas han contribuido a las nuevas políticas estatales y al cambio de las dinámicas tradicionales de desconcentración de la educación superior.

En general, en la región, el aumento de las demandas entró en confrontación con las desigualdades e inequidades existentes en el funcionamiento de los sistemas de educación superior que limitaban su propia masificación (Montecinos, 2013). Esas demandas insatisfechas de acceso y los tipos de mecanismos políticos o de los mercados educativos han presionado - y, a la vez, han facilitado - los cambios mediante la regionalización universitaria. Esto es un proceso político de intereses diferenciados y, por ende, no es un proceso lineal, sino que será el resultado de las diversas resistencias en las estructuras de funcionamiento e incluso de los diversos actores, tanto académicos como políticos urbanos reticentes a perder poder, matrícula o calidad en los procesos de enseñanza. En este sentido, el curso y las características que la regionalización asume son un fenómeno político de cada país, de su sistema universitario y de sus marcos normativos, y de las universidades dominantes y de las ideas y paradigmas sobre la democratización de los accesos ${ }^{1}$. En este sentido, las modalidades que asume o no la regionalización son el resultado de las luchas locales frente a los poderes centrales, de las dinámicas internas de las estructuras monopólicas y autónomas universitarias en varios países de la región, y de las formas que tiene la competencia interuniversitaria en cada país. Todas ellas son las que crean las resistencias y, por ende, marcan las formas que asume la diferenciación institucional como parte de la regionalización universitaria.

Los análisis tienden a diferenciar la regionalización universitaria en dos orientaciones (Charfic, 2009; Finot, 2001). Las primeras orientaciones, marcadas por dinámicas de desconcentración, se expresan en sedes y filiales que no transfieren poder educativo y tienden a menores niveles de pertinencia y calidad. Las segundas, marcadas por una descentralización por medio de nuevas instituciones, tienden a promover mayores empoderamientos socioacadémicos $y$, por ende, potencialmente mayores niveles de pertinencia y, por ende, también de calidad. Mientras las primeras producen sistemas más homogéneos, las segundas tienden a fragmentar el sistema de educación superior en múltiples actores, tipologías e instituciones. Mientras las primeras tienden a sistemas menos diversos e instituciones

1 El debate entre educación de castas y educación de masas representado entre Arturo Uslar-Pietri y Luis Beltrán Prieto-Figueroa en Venezuela en los 40 fue una expresión de estas visiones (Prieto-Figueroa, 2009). 
centrales más grandes y con mayores escalas y tamaños, la otra es parte de la diferenciación socioeducativa que deriva en microuniversidades con carencias de escala para ofrecer algunos servicios con calidad. Es el complejo dilema de la gestión, la concentración y la pertinencia, lo global y lo local.

Desde mediados de los 70, la diversificación institucional pública y privada en la región ha impulsado una regionalización que ha reducido las desigualdades universitarias entre el interior y las capitales, y entre docentes y mercados laborales. Sin embargo, las formas de esa regionalización han sido diferentes en los distintos países en términos de ingreso, permanencia y egreso, con un impacto distinto en la creación de las capacidades locales y de sus niveles de empoderamiento y, por ende, en la propia calidad de la enseñanza. Esta regionalización fue dominantemente una desconcentración universitaria, expresada en sedes o en educación a distancia.

La investigación comparada devela, en los últimos tiempos, un cambio en la entonación tradicional de la regionalización como desconcentración y una mayor entonación de una regionalización vía descentralización institucional mediante la creación de nuevas instituciones y, a la vez, está siendo acompañado e impulsado por la irrupción de nuevas modalidades de regionalización y de tipologías universitarias. En este nuevo curso de la regionalización, influyen las tecnologías educativas, la mayor dinámica competitiva entre el sector público o privado, y los nuevos desarrollos económicos y sociales de las regiones y de sus fuerzas sociales que impulsan un mayor empoderamiento regional. Esta dinámica parece tener como trasfondo una diferenciada relación entre los gobiernos nacionales y las regiones en la educación superior que antes era visto solo como un tema capitalino.

La regionalización de la educación superior siempre ha sido en América Latina el resultado de una dinámica política de negociación y conflicto que ha derivado en distintas formas de desarrollo institucionales, en función de cómo se han procesado las tensiones alrededor de la construcción del capital humano y de las luchas políticas alrededor del empoderamiento de las regiones. La forma en que se resuelven esas tensiones es la variable determinante de la diversidad de formas que está asumiendo actualmente la regionalización de la educación superior de toda la región. Ello ha planteado un cambio y la irrupción de nuevos particularismos y diferencias en las modalidades que asumía la regionalización.

A continuación, realizamos una caracterización de las distintas regionalizaciones de la educación superior en curso en la región atendiendo a sus particularidades institucionales, académicas y de gestión, para mostrar la mayor diferenciación de las tipologías tradicionales de regionalización, una mayor intensidad de las formas de descentralización y un cambio en las formas de desconcentración que marcan a su vez una mayor intensidad en el uso de la educación a distancia y virtual.

\section{La diversidad de modelos de regionalización universitaria en la América Latina}

\section{La regionalización por medio de sedes universitarias}

La modalidad de regionalización universitaria dominante en América Latina ha sido la instalación de sedes y subsedes de las universidades tradicionales de las capitales o de las capitales departamentales en el interior de los países. Ello se ha expresado en una desconcentración universitaria con baja diferenciación institucional, escaso empoderamiento local y cuyas ofertas tienden a tener escasa pertinencia regional. Esto constituyó un modelo de expansión territorial que al tiempo contribuyó a la cons- 
titución de macrouniversidades y se constituyó en la forma dominante de regionalización del sector público e incluso privado de la educación presencial. Ello facilitó mayores niveles de cobertura y de escalas de las universidades como resultado de estas extensiones y sedes. Ello también permitió curvas de experiencia que tornaron más fácil la continuación de las dinámicas de crecimiento mediante la creación de diversidad de sedes y filiales.

La expansión de esta modalidad ha dependido de los marcos legales. Así, por ejemplo en Argentina y Bolivia, no se autoriza a las universidades públicas tradicionales a ofertar fuera de su circunscripción provincial o departamental. Esta regionalización a partir de sedes en todo el territorio nacional tiende a crear dinámicas altamente homogéneas con bajo empoderamiento. Claramente, la desconcentración vía sedes ha sido la figura de regionalización de las universidades monopólicas en países donde carecen de competencia, como Guatemala, República Dominicana, Honduras, El Salvador, Uruguay y Puerto Rico, y facilitó su conformación como macrouniversidades. En algunos países, la regionalización a partir de sedes ha sido impulsada desde las universidades localizadas en las ciudades secundarias en las regiones, departamentos o Estados, para cumplir un rol de municipalización con sedes en el tercer nivel del Estado.

La expansión pública a partir de sedes reduce las desigualdades e inequidades regionales en el acceso, pero también se manifiesta en limitados niveles de pertinencia y empoderamiento regional pues funciona como una mera desconcentración administrativa de la prestación del servicio (Moncayo, 2002). Esta regionalización por medio de sedes varía en función del nivel de competencia de los distintos mercados universitarios. La existencia de sedes no anula la creación de universidades. Tal es el caso de la regionalización de la Universidad de Buenos Aires (UBA), la más grande de la región, que se expandió en la provincia de Buenos Aires por medio de decenas de sedes, que compiten con las universidades públicas nacionales en función de la calidad y del valor de las distintas certificaciones. Sin estas sedes, la UBA no sería la universidad más grande de la región.

Inversamente, cuando la regionalización por sedes está asociada a condiciones de monopolio, como han sido los casos de Guatemala (Universidad de San Carlos, USAC)², de República Dominicana (Universidad Autónoma de Santo Domingo, UASD)3, El Salva-

2 La Universidad de San Carlos (USAC) alcanza 85.000 estudiantes localizados en 20 sedes correspondientes a 20 de los 22 departamentos.

3 La Universidad Autónoma de Santo Domingo (UASD) de República Dominicana es la tercera en tamaño de las universidades públicas dor (Universidad de El Salvador, UES) ${ }^{4}$ o en Uruguay (Universidad de la República, UdelaR), el impacto es de menor intensidad en términos de pertinencia, empoderamiento y eficiencia competitiva, y se reproducen los monopolios en las regiones.

En Uruguay, por ejemplo, la UdelaR impulsó una regionalización a escala nacional bajo una lógica de monopolio, al no existir una competencia de otra oferta pública, pero ello se realizó con ofertas locales que no competían con las ofertas de la sede central en la capital del país, sino que propendían a una relativa pertinencia local. Impulsada esta regionalización desde 2007 con el inicio de la construcción de infraestructura (sedes en Salto, dos regionales en el este y un polo de desarrollo universitario del noreste), ella se apoyó en el objetivo de que "la UdelaR tenga un rol clave en el desarrollo local, regional y nacional", a partir de la especialización de las ofertas en las distintas sedes de acuerdo al medio ambiente donde están inscritas más allá de su alta dependencia administrativa (Musto, 2012).

A medida que los sistemas universitarios se tornan más diferenciados con diversidad de instituciones, en especial privadas, el mantenimiento de sus dimensiones relativas de las universidades las lleva a aumentar su cobertura en el interior de los países y regiones con subsedes y a incrementar su matrícula de estudiantes totales y regionales. Sin embargo, estos procesos de desconcentración se realizan con las mismas ofertas y docentes que se trasladan desde las capitales y, por ende, mantienen la concentración de los recursos con escaso empoderamiento y reducida cantidad de recursos humanos y económicos que se desconcentran ${ }^{5}$.

de la región. Para 2013, tenía 19 centros regionales en todo el territorio con una matrícula combinada de 170.530 (2010), el 47\% de la matrícula nacional universitaria (363.952). Más del 30\% de su propia matrícula está distribuido en las sedes provinciales localizadas en varias de las 32 provincias del país. En este caso, la diferenciación pública ha sido casi nula y se ha desarrollado un modelo público de universidad, sistema por el cual se cubren las demandas de acceso en la capital apoyado con una regionalización por sedes en todo el país. Este formato de expansión ha sido facilitado por la autonomía (Ley 5778/1961).

4 La Universidad de El Salvador es monopólica en el sector público y se regionalizó por 3 sedes regionales en los departamentos de Santa Ana, San Miguel y San Vicente, localizadas fuera del campus central donde funcionan nueve facultades.

5 El análisis de un caso de un modelo monopólico universitario público como la UdelaR del Uruguay es un claro indicador de los niveles de desigualdad. Los censos realizados en esa universidad muestran el crecimiento de la matrícula del interior: en 1999 (V Censo) el 32\% de los estudiantes provenía del interior, en 2007 (VI Censo) ese indicador se había ampliado a 36\%, y en 2012 (Censo VII de estudiantes de grado) era 38\%. Entre 1999 y 2012, los estudiantes del interior en esa universidad han pasado de representar $14,7 \%$ a $22,9 \%$, con un crecimiento de $66 \%$ en 13 años, pero muy lejos de dar cobertura igualitaria a escala nacional al $60 \%$ de la población que nació en el interior (Grille, 2013). 
En muchos casos, la mera desconcentración limita la pertinencia de los programas de las subsedes, pues sus programas académicos no están estructurados en función de su pertinencia local sino que son copia de los programas académicos diseñados para las capitales ${ }^{6}$. Esta dinámica crea una continua tensión entre la sede central y las sedes regionales, lo que complejiza la gestión de las universidades al crear conflictos alrededor de la distribución de los fondos, la diferenciación de la calidad y los niveles de autonomía y libertad de las sedes. Esta tensión interna limita y determina el grado de regionalización en el marco de una discusión permanente asociada a la distribución del poder y de los recursos entre la sede central y las regionales, las subsedes y las filiales. Con ello, la desconcentración presiona hacia abajo los niveles de eficiencia a medida que se expanden las sedes y se complejiza la gestión. En tal sentido, la eficiencia tiende a ser inversamente proporcional a la cantidad de sedes y, además, a medida que estas se expanden, los gastos de control, supervisión y estandarización aumentan. En general, las sedes carecen del empoderamiento administrativo y académico requerido para una gestión con pertinencia y calidad y la delimitación de las responsabilidades y autonomías deriva en concepciones diferenciadas de poder, calidad o control.

Muchas universidades regionales públicas también han desarrollado procesos de subregionalización y desconcentración al crear subsedes, con lo cual logran aumentar escalas y coberturas, y cubrir demandas insatisfechas generalmente en el tercer nivel del Estado, e impulsar la municipalización de la educación superior. Esto ha sido importante en México y Brasil, y también en casi toda la región en los últimos años. En algunos casos, estas subsedes han sido la base sobre la cual se han creado nuevas universidades estatales, federales o nacionales que se han expandido en los municipios. Estas subregionalizaciones en algunos casos han introducido nuevos modelos pedagógicos, fundamentalmente por medio de ofertas semipresenciales en las sedes, como la Universidad de Guadalajara en México, con sus casas universitarias. Estas dinámicas también han tenido sus excesos como en Chile, donde la Universidad de los Lagos ha alcanzado 45 sedes, bajo una dinámica altamente mercantil que ha derivado en una caída de la calidad expresada en su no acreditación, lo que muestra la relación entre calidad y alta cantidad de procesos de enseñanzas desconcentrados en sedes.

En Brasil, la municipalización ha sido un proceso independiente y dinámico de descentralización, con

6 En Costa Rica por ejemplo, los programas de las sedes son "propiedad" del claustro de la Facultad de la sede central por lo que su cambio y su pertinencia local son muy dificultosos. universidades municipales creadas por los municipios y administradas autónomamente bajo el régimen del derecho privado y por consejos con amplia participación social.

La lógica de organización institucional de la relación entre las subsedes y la central ha constituido uno de los ejes de la eficiencia institucional en el sector privado. El Sistema Tecnológico de Monterrey -el Instituto Tecnológico y de Estudios Superiores de Monterrey, la Universidad TecMilenio, Tec Salud, conformado por la Escuela de Medicina y Ciencias de la Salud, el Hospital San José y el Centro Médico ZambranoHelion, y Sorteos Tec- l luego de una fase muy rápida y desordenada de creación de 26 campus universitarios, se planteó dos caminos: cerrar varios centros o crear una infraestructura física de campus de igual porte así y de similar nivel académico para que todas las sedes tuvieran los mismos niveles de calidad y a la vez establecer sistemas administrativos y financieros de soporte en cada uno de ellos que permitieran un adecuado proceso de control y seguimiento. Esto derivó en la conformación de un modelo de gestión que centralizó el diseño de los planes de estudio, los métodos administrativos, la misión y los sistemas de control de la calidad, generó una fuerte burocracia central y descentralizó los aspectos operativos sobre la base de dinámicas de inversiones, salarios y recursos humanos de igual dimensión (Rangel-Sostmann, 2014). Ello creó un sistema universitario TEC con los mismos estándares y el valor nacional de sus certificaciones, pero no pudo alcanzar las escalas rentables de las ofertas con el objetivo de unidad de costos diferenciados, e igual nivel de calidad; esto llevó a que las sedes locales dejaran de ser parte de esa "marca" del grupo empresarial y se transfirieron a otra institución creada por el grupos con distinto perfil y que se llamó TEC Milenio. La diferenciación institucional fue entonces el mecanismo para mantener la desconcentración pues los recursos no permitían una oferta similar a escala nacional bajo la marca tradicional del TEC que se posicionó en un mayor nivel de calidad.

\section{De las sedes a las universidades como modelo de regionalización}

En varios países, la regionalización pública por medio de sedes ha dado lugar a la transformación de estas sedes en universidades. Esto siempre ha sido un proceso traumático de rupturas y en la mayor parte de los casos, requirió la confluencia de los actores internos con el sistema público de gobierno y/o legislativo. Ello se dio en Chile como modelo de política pública desde 1981. Allí, la creación de universidades públicas en el interior se dio muy tempranamente con el nacimiento de la Universidad de Antofagasta, a partir de la Escuela Industrial del Salitre (1918) y de la 
Universidad de Concepción (1919)7. Sin embargo, la modalidad dominante de regionalización fue la de la desconcentración mediante la creación de sedes regionales de la Universidad de Chile y de la Universidad Técnica del Estado en las décadas del 60 y del 70. La Ley General de Universidades de 1981 cambió tal dinámica drásticamente, y creó otro modelo de regionalización mediante la descentralización, por el cual estas sedes se autonomizaron y se unificaron al separarlas de sus respectivas matrices y dar origen a nuevas universidades públicas regionales ${ }^{8}$. A partir de entonces, las universidades solo tendieron a crear sedes en su propia región y se expandió una dinámica de universidades regionales y mayor diferenciación institucional. La desconcentración universitaria mediante sedes en todo el país se limitó y con ello se limitó el aumento de la escala de las universidades capitalinas. La división de las unidades académicas de ambas instituciones fue el eje de la política de la dictadura de Augusto Pinochet [16 de diciembre de 1974-11 de marzo de 1990] para limitar el poder político de las universidades públicas, continuó incluso posteriormente bajo el régimen democrático luego de la caída de la dictadura. Así, en 1993 se produjeron nuevos procesos de regionalización mediante desprendimientos de varias unidades académicas de sedes desconcentradas de la Universidad de Chile que derivaron en la creación de la Universidad Tecnológica Metropolitana, el 30 de agosto de 1993.

Más recientemente, el 3 de agosto de 2015, el gobierno de Michelle Bachelet presentó un proyecto de ley de creación de dos nuevas universidades regionales en O’Higgins y Aysén, las dos zonas que carecían de universidades propias. El proyecto fue aprobado y con ello se completó el ciclo de creación de universidades públicas en cada región del país. Al tiempo se prohibió que las universidades públicas ofertaran fuera de sus

7 La historia de la Universidad de Concepción como muchas de las universidades regionales muestra la lucha de hombres que levantaron las banderas contra el gobierno central. En este caso, luego de muchas diligencias y de diversas conversaciones: "'el Comité se convenció de que el Gobierno no crearía quién sabe en cuánto tiempo la Universidad. No eran solo penurias financieras que lo impedían, habían (sic) también de por medio rivalidades, temores políticos y sectarios y no faltaba tampoco la menguada entrega de alguna pequeñez humana', señalaba en 1929 Enrique Molina en la celebración del décimo aniversario de la Universidad. Agregando, que por tal motivo: 'El Comité se cansó de esperar y en un gesto de audacia y de fe resolvió, sin más ni más, abrir la Universidad a principios de 1919'" (https://www.udec.cl/ pexterno/node/164?q=node/166)

8 Ellas fueron la Universidad de Atacama, UdA (Atacama), 26 de octubre de 1981; la Universidad Arturo Prat, UNAP (Tarapacá), creada en 1967, y continuadora del Instituto Profesional de lquique (fundado en 1981), derivado a la vez de una sede más pequeña y joven de la Universidad de Chile. La Universidad de La Serena (Coquimbo), fundada en 1981, resultó de la fusión de las sedes de la Universidad de Chile y de la Universidad Técnica del Estado; Valparaíso (Valparaíso), 12 de febrero de 1981; Universidad de La Frontera (Araucanía), que nace como institución autónoma el 10 de marzo de 1981, tras la fusión de las sedes en Temuco de la Universidad de Chile y la Universidad Técnica del Estado. La Universidad de Talca (Maule) fundada el 26 de octubre de 1981, tras la fusión de las antiguas sedes de la Universidad de Chile y la Universidad Técnica del Estado (UTE), y que tiene su casa central en la ciudad de Talca, capital de la región del Maule, cuenta hoy con tres campus emplazados en las ciudades de Curicó y Santa Cruz (Colchagua) y en Santiago. También es la situación de la Universidad del Bío (Bío Bío), 29 de septiembre de 1988. En el caso de esta institución, la legislación de 1980 que obligó a convertir las sedes regionales en universidades, de acuerdo con el concepto de regionalización y desconcentración, dio lugar al surgimiento del Instituto Profesional de Chillán (IPROCH), ya que entre sus carreras no figuraba ninguna de las consideradas universitarias. En 1988, se produjo la fusión de la Universidad de Bío con el Instituto Profesional de Chillán, que dio origen a la que es hoy la Universidad del Bío-Bío. Mediante el Decreto con Fuerza de Ley 150, del 11 de diciembre de 1981, se creó la Universidad de Tarapacá, que fusionó el Instituto Profesional de Arica con la sede Arica de la Universidad del Norte. Bajo este modelo también se creó la Universidad de Magallanes, fundada como sede de la antigua Universidad Técnica del Estado en 1961. También es de destacar la creación de la Universidad de Los Lagos (Los Lagos, Osorno). 
regiones y se les otorgó de hecho el monopolio de oferta en las regiones donde están instaladas.

Panamá también ha implantado el modelo de regionalización mediante la instalación de sedes de universidades nacionales y luego transformadas en universidades independientes (y autónomas), con la creación de la Universidad Autónoma de Chiriquí (UNACHI), que se desprendió de la sede regional de la Universidad de Panamá. En Nicaragua, la junta de gobierno de reconstrucción nacional en 1982 dividió la Universidad Nacional Autónoma de Nicaragua (UNAN) en UNAN-León y UNAN-Managua, ubicadas respectivamente en León y en la capital Managua como universidades autónomas independientes ${ }^{9}$. Múltiples universidades federales brasileñas y nacionales argentinas también tienen su génesis en las sedes de otras universidades.

Inversamente, los bloqueos a los intentos de conformar nuevas universidades como derivación de procesos de autonomización de las subsedes regionales han sido muchos en la región. Un caso significativo ha sido el intento de autonomizar, por parte de diversos diputados, de la sede de la Universidad Nacional Autónoma de Honduras (UNAH) en San Pedro Sula con más de 15.000 estudiantes y cuyo escaso nivel de autonomía impone bajos niveles de calidad y de pertinencia. El eje de las resistencias está en los cuerpos académicos y las lógicas corporativas que temen perder los beneficios presupuestales que la Constitución Nacional otorga a la UNAH. En Argentina, la permanente nacionalización de las universidades provinciales, impulsada por la existencia de salarios diferenciados entre los niveles nacionales y provinciales, es uno de los factores de resistencia a la regionalización institucional de las universidades por parte de los cuerpos académicos.

La regionalización mediante la creación de nuevas universidades públicas

En la región, algunos países establecieron un régimen especial para universidades coloniales y republicanas, como universidades mayores o nacionales que les otorgaba un estatus diferenciado o incluso único. Con el tiempo, muchas de estas instituciones asumieron la forma de macrouniversidades, como resultado de la baja diferenciación institucional en el conjunto del sistema y de su regionalización mediante subsedes. Con ello, la expansión de la cobertura se produjo con una diferenciación dentro de estas universidades que acompañaron la expansión de la demanda con múltiples sedes y no mediante la creación de nuevas universidades. Ello constituyó una dinámica de regionalización mediante la desconcentración universitaria. Sin embargo, en algunos países de la región, hubo dinámicas de regionalización por la creación de nuevas universidades que impulsaron procesos de descentralización institucional y que facilitaron con ello la conformación de sistemas universitarios más diferenciados y competitivos.

En el primer caso, las instituciones asumieron mayores escalas y dimensiones y la expansión de la cobertura se produjo con una reducida diferenciación institucional. Ello diferenció entre procesos de masificación por los cuales algunas universidades se expandieron por mayores escalas con más diversidad de ofertas y regionalizaciones con múltiples sedes. Esta dinámica conformó una lógica institucional en la cual la universidad era un sistema universitario. Por otra parte, también se produjeron modalidades de regionalización caracterizadas por una diferenciación institucional y una lógica de descentralización sistémica que tendió a construir sistemas

9 En este caso, la división es de una universidad regional, ya que la sede de la universidad creada en 1812 era en León, mientras la filial estaba en Managua. La división respondió al deseo de los cuerpos académicos de la capital de no depender de los cuerpos académicos del interior. 
universitarios diferenciados con diversidad de instituciones, mayor competencia institucional y menores dimensiones relativas de las universidades dentro de los sistemas universitarios nacionales.

En los países donde algunas universidades tuvieron un rol monopólico legal y, por ende, la diferenciación fue nula o muy reducida, como Guatemala, El Salvador, Haití, República Dominicana, Paraguay y Uruguay, y en menor proporción durante muchos años Panamá, Nicaragua y Honduras, estos monopolios se conformaron como macrouniversidades por sus altas escalas, la pluralidad de ofertas y de sedes y su comparación relativa con otras instituciones. Sin embargo, al tiempo, la baja competencia institucional y el alto centralismo administrativo y académico del funcionamiento de las sedes regionales han impactado en sus menores niveles de calidad respecto a la sede central. Estos impactos de las sedes locales también han determinado menores niveles de calidad de la propia institución.

Estas lógicas han comenzado a ser historias del pasado. Así, en las últimas décadas con distinta intensidad, en varios países, ha habido un cambio y se ha asistido a una dinámica de regionalización universitaria, no sobre la base de la expansión interna de las universidades, sino mediante la creación de nuevas universidades. Ello está contribuyendo a conformar sistemas universitarios públicos o privados más diversificados y complejos, con múltiples instituciones, aun cuando - en algunos casos - con niveles de autonomía diferenciados entre las nuevas y las viejas instituciones. La descentralización limitó indirectamente la prestación del servicio exclusivamente por las llamadas macrouniversidades tradicionales, todas las cuales han reducido su participación en la matrícula total. Al tiempo, en algunos casos, esta reducción de la incidencia en la cobertura ha estado acompañada por un aumento en la calidad, la oferta de posgrados y la mayor investigación.

En las décadas anteriores, la regionalización institucional del sector público mediante la creación de universidades tuvo un relativo protagonismo acompañado de masificación. Entre otros casos, en Venezuela se destaca la política de creación de universidades experimentales con el marco específico de la Ley de Universidades de 1970 y el Reglamento Parcial de la Ley de Universidades de 1971, o en Chile con la Ley General de Universidades de 1981, que impuso la unificación de las sedes regionales y su transformación en universidades. En Brasil, se produjo la expansión de varias universidades estatales en los ochenta, mientras que en México hubo continuidad y aumento de la creación de universidades estatales, que han llegado a cubrir los 32 estados de la federación. En Argentina, la creación de universidades nacionales en el interior se expresó en el proyecto integrado Plan Taquini (2000) y posteriormente con la creación de universidades públicas en los distintos partidos ${ }^{10}$, municipios alrededor de la ciudad de Buenos Aires en los noventa. Desde los 70, en Costa Rica, se verifica en la creación de tres nuevas universidades públicas. En Nicaragua se realizó mediante la división de la Universidad Nacional Autónoma de Nicaragua ${ }^{11}$, y en Panamá en relación con la Universidad de Panamá que derivó en la creación de la Universidad Tecnológica.

Más allá de las diferencias políticas, como el régimen de Augusto Pinochet en Chile, el Frente Sandinista de Liberación Nacional, FSNL, en Nicaragua o los sistemas democráticos consolidados en Venezuela, Costa Rica, México o Argentina, en varios países de la región desde los 70 hubo una diversificación del sector público que se expresó en una relativa regionalización mediante la creación de nuevas universidades públicas, lo cual implicó un diferenciado grado de descentralización, autonomía y empoderamiento respecto a las universidades públicas tradicionales existentes ${ }^{12}$.

En Perú, Argentina, Bolivia, México, Venezuela, Chile, Ecuador, Paraguay y Brasil, la demanda regional por acceso a la educación superior, se respondió desde el sector público mediante la creación de instituciones universitarias en cada una de las unidades administrativas del país. La creación de sedes fuera de los departamentos, por parte de las universidades allí localizadas, estuvo limitada en algunos países con miras a no introducir competencia entre las instituciones. En general, estas limitaciones facilitaron un modelo de regionalización ordenado y fragmentado de las universidades públicas con espacios de acción claramente delimitados. En ellos varió sin embargo la adscripción y dependencia política. Mientras que en México y Brasil hubo un peso destacada de los gobiernos estatales en la fiscalización, en los otros casos dependieron de los gobiernos nacionales, por lo que el empoderamiento era más limitado.

10 Partidos es la denominación administrativa de los municipios o tercer nivel del Estado en la provincia de Buenos Aires.

11 Actualmente, hay dos UNAN, resultado de un Decreto de la Junta de Gobierno de Reconstrucción Nacional (JGRN) en 1982 que la dividió en UNAN-León y UNAN-Managua, ubicadas respectivamente en León y en la capital Managua.

12 En Venezuela, ello se expresó en la Ley de Universidades de 1970 y el Reglamento Parcial de la Ley de Universidades de 1971, en Argentina en el Plan Taquini, mientras que en Costa Rica ello se produjo con la creación de varias universidades públicas (Universidad Nacional de Costa Rica, UNA, Centro de Desarrollo Profesional, INTEC y Universidad Estatal a Distancia, UNED) como parte de un proyecto de diferenciación universitaria frente al monopolio de la Universidad de Costa Rica. En México, se produjo un largo proceso iniciado en 1917 que concluyó en la década del 90. Igualmente, ello se ha desarrollado en Brasil, mediante la expansión de universidades estatales. 
Bajo esta modalidad de regionalización, en diversos momentos se han ido creando universidades públicas en las diversas unidades administrativas, fundamentalmente en el segundo nivel del Estado. Ello contribuyó a un mayor empoderamiento de las regiones, con sus propias diferenciaciones según el grado de fiscalización nacional o regional en lo administrativo y del grado de dependencia de las universidades de los poderes centrales o de sus niveles de autonomía de la gestión frente a los poderes regionales. En Argentina, Bolivia, Paraguay, Perú y Chile más allá de su localización regional las universidades públicas eran nacionales por su dependencia financiera y académica del Gobierno Nacional. En México y Brasil, ello se ha expresado a la vez tanto en la creación de universidades nacionales como en universidades estatales o provinciales con dependencia de los poderes regionales o del segundo nivel de organización del Estado. En Brasil, ello también se expresó en la habilitación a la creación de universidades municipales correspondientes al tercer nivel de los Estados.

En la década de 2000, en toda la región hubo un cambio en la dinámica de regionalización, dado por una mayor intensificación de la creación de nuevas universidades frente a los procesos de mera desconcentración, como veremos a continuación para el caso de algunos países de la región donde esto fue más notorio. Este proceso se produjo en una dimensión superior a las creaciones acontecidas en la década del 90, y reafirmó una mayor intensidad de la descentralización institucional a escala regional, a la vez que restringió el potencial de diversificación interna de las universidades desde las capitales mediante la desconcentración en subsedes. El aumento de recursos públicos y de las demandas de acceso, y la revalorización de la educación como bien público han impulsado esta política. Ella ha contribuido a aminorar significativamente también la tasa de crecimiento de la educación privada (Rama, 2012a).

La regionalización mediante la descentralización universitaria con sus propios matices en los países de la región se analiza a continuación.

\section{a. Argentina}

En Argentina, la regionalización ha estado marcada por un proceso pendular de tensiones entre su carácter de adscripción a las provincias y a la Nación como parte de una dinámica de empoderamiento limitado y de centralización política (Rama, 2014). Las universidades dominantes son universidades nacionales creadas por el gobierno y financiadas y reguladas por el gobierno Federal, pero localizadas en una provincia en particular. Desde los años 2000, esta orientación de conformación del sistema se ha vigorizado y desde 2003 las universidades públicas han aumentado en 9 universidades nacionales, 6 de las cuales están ubicadas en el conurbano bonaerense y 3 en el resto del país ${ }^{13}$. En 2013, se creó la Universidad Nacional de Hurlingham que se suma a las 5 universidades creadas en el conurbano desde 2007. La sanción fue con 134 votos positivos, 16 en contra y 41 abstenciones. En octubre de ese año, el Congreso Nacional aprobó la estatización del Instituto Universitario Nacional de Derechos Humanos Madres de Plaza de Mayo (antigua Universidad Popular de las Madres de Plaza de Mayo). En esa misma sesión del Congreso Nacional, se votó la transformación de la Universidad Nacional de las Artes, UNA, que reemplazó al Instituto Nacional de las Artes (IUNA), y la creación de la Universidad Nacional de los Comechingones, en la Provincia de San Luis. También se dio media sanción a la "nacionalización" de dos universidades provinciales, la de Ezeiza y la Pedagógica y se giró al Senado la aprobación de otras cuatro nuevas universidades kirchneristas: Rafaela (Santa Fe), Raúl Scalabrini Ortiz (San Isidro), Nacional del Alto Uruguay (Misiones) y Guillermo Brown (Almirante Brown). El proyecto de Universidad Nacional de Hurlingham había sido rechazado por el Consejo Interuniversitario Nacional (CIN).

La expansión de universidades en el espacio conurbano de Buenos Aires ha sido un proceso activo desde los años 90. Inicialmente, se localizaron en el llamado primer cinturón de la provincia de Buenos Aires, y en la década pasada, se pasaron a crear universidades en el llamado segundo cinturón compuesto por múltiples villas y poblados. Ello ha propendido a limitar la expansión de sedes de la Universidad de Buenos Aires que cuenta con 38 sedes, doce de las cuales son centros regionales distribuidos en toda la provincia. Las nuevas universidades nacionales también se han gestado como mecanismos de acción política partidaria sobre la base de un modelo de articulación entre los partidos o municipios y las universidades en un entorno urbano específico y altamente dependiente de los "punteros" políticos locales y de los intendentes del partido de gobierno en estas localidades. Aunque las nuevas instituciones tienen adscripción al gobierno nacional y se rigen por un modelo homogéneo de autonomía y cogestión, se han estructurado sobre la base de una articulación política a las fuerzas políticas en los partidos locales (Debesa, 2013).

13 Estas nueve universidades son la Universidad Nacional Arturo Jauretche (Florencio Varela - Buenos Aires); Universidad Nacional de Avellaneda (Buenos Aires); Universidad Nacional de Chilecito (La Rioja); Universidad Nacional de Moreno (Buenos Aires); Universidad Nacional de Río Negro; Universidad Nacional de Tierra del Fuego e Islas del Atlántico Sur; Universidad Nacional de Villa Mercedes (San Luis); Universidad Nacional del Chaco Austral; y la Universidad Nacional del Oeste (Merlo, Buenos Aires). 
La regionalización universitaria mediante universidades nacionales con localización en las diversas provincias y partidos, ha tenido un desarrollo histórico continuo desde inicio del siglo XX. En las provincias, ellas a su vez se han expandido a través de subsedes regionales. Sin embargo, desde los 90, se ha asistido a la creación de universidades en provincias que ya tenían una universidad, y fuera de la sede central de esta, de nuevas universidades nacionales. Ello impactó en el modelo de sedes en las provincias y anuló el intento de construir universidades provinciales. Esta figura institucional había sido prevista en la ley 17.778 del 12 de junio de 1968 que facultó la creación de esta modalidad institucional de regionalización universitaria. Fue introducido por el presidente Juan Carlos Onganía durante su período militar (29 de junio de 1966-8 de junio de 1970), como estructuras altamente dependientes del poder ejecutivo y sin autonomía, pero con adscripción a las provincias. Antes de la fundación de la universidad por la provincia, esta ley requería la aprobación de un Decreto del poder ejecutivo en el cual se prestase conformidad con el proyecto; que toda modificación de las carreras, títulos, grados y otros cambios tuvieran un nuevo acuerdo del poder ejecutivo, y que no podían tener cogestión ya que sus órganos de gobierno solo podían estar integrados por profesores universitarios. Como política de largo plazo, la ley creó el Consejo de Rectores de las Universidades Provinciales como órgano de consulta.

Ninguna institución sin embargo se desarrolló bajo ese marco normativo y la ley fue derogada en 1995, ya en democracia, cuando se creó la nueva institucionalidad normativa con la Ley de Educación Superior que reafirmó un modelo autonómico público de universidades nacionales localizadas en una región o provincia particular con supeditación presupuestaria y académica al gobierno central por medio de una Secretaría de Políticas Universitarias (SPU) del Ministerio de Educación y del Consejo Nacional de Evaluación y Acreditación Universitario (CONEAU) con amplia participación del ámbito político parlamentario.

La Ley en su artículo 15 determinó que a las provincias y a la municipalidad de la ciudad de Buenos Aires solo les compete el gobierno y organización de la educación superior no universitaria en sus respectivos ámbitos de competencia y, por ende, solo están facultadas para dictar normas que regulen la creación, modificación y cese de este tipo de instituciones de educación superior no universitarias ${ }^{14}$. Ello reafirmó una regionalización fragmentada: por un lado mediante la creación de universidades nacionales localizadas en las provincias, y con baja o nula acción fuera de estas, con escasos niveles de articulación institucional con los gobiernos locales, sujetas al control, a los estándares y el financiamiento del poder ejecutivo, pero autónomas y cogestionadas. Por el otro lado, por medio de instituciones no universitarias y terciarias provinciales o privadas centradas en cursos cortos en formación docente, tecnológicas o artísticas, como instituciones heterogéneas, carentes de planificación, terminales y que desde 1993 están sujetas a los gobiernos provinciales (Sigal \& Dávila, 2005).

En estos últimos años, al calor de un cambio en la importancia económica de las provincias, de búsqueda de cumplimiento de los marcos federales constitucionales y de un mayor empoderamiento regional, se han creado universidades provinciales, en Chubut, Entre Ríos, San Luis y Córdoba. Ellas representan una diferenciación de la tipología en el panorama institucional, una nueva modalidad de regionalización y un espacio de tensión entre los poderes nacionales y regionales. Expresan la idea de una uni-

14 Argentina, Ley 24.521, Ley de educación superior, 20 de julio de 1995. Disponible en: http:// www.me.gov.ar/spu/legislacion/Ley_24_521/ley_24_521.html 
versidad pública en el segundo nivel del estado pero creada y supervisada por las provincias como segundo nivel en la organización del Estado. Ellas, sin embargo, no han sido reconocidas completamente y han mostrado el conflicto entre las provincias y la Nación respecto a las modalidades de regionalización en educación superior (Rama, 2014). Este largo debate encontró un nuevo momento recientemente con la aprobación en noviembre de 2015 de la reforma de la Ley de educación superior 24.521, sancionada en 1995, que entre otros elementos dispone que sean "las provincias y la Ciudad Autónoma de Buenos Aires las responsables de proveer el financiamiento, la supervisión y fiscalización de los Institutos de Formación Superior de sus distritos y casas de altos estudios provinciales"15.

\section{b. Brasil}

En el caso de Brasil, en el sector público en 2004 había 224 instituciones, el $11,1 \%$ del total nacional, consistentes en 87 universidades federales, 75 universidades estaduales y 62 universidades municipales. Para 2011, el total de universidades públicas era de 284 con un aumento de 60 nuevas instituciones, lo que representa un incremento de $27 \%$ en la cantidad de universidades del sector público. De esta cifra, a las universidades federales correspondió un aumento de 16 para alcanzar 103 (incremento de 18\%); las estatales alcanzaron 110 con un aumento de 35 instituciones que representó un aumento de $47 \%$ y las universidades municipales alcanzaron 71 a escala nacional con un aumento de 9 instituciones, o sea, el 14\%: el menor en términos absolutos y relativos. En este caso, la regionalización de la universidad pública en el segundo nivel del Estado, los Estados, y estos asumen la gestión y el financiamiento.

\section{c. Ecuador}

Históricamente, Ecuador desarrolló una fuerte regionalización universitaria como resultado de las dinámicas políticas democráticas y una orografía y localización dispersa facilitada por el impulso de los representantes de las distintas provincias que fueron conformando una relativa regionalización de la educación superior en el país pues la Constitución otorgó al Congreso Nacional ser el ámbito de decisión de creación de universidades. Diversas fuerzas y economías regionales de Cuenca, Pichincha, Guayaquil y Loja fueron impulsando sus propias universidades ya en el siglo XIX y principios del siglo XX, como parte de procesos federales y de luchas de poder en la construcción de la unidad nacional. En el siglo XX se fueron creando nuevas universidades en todas las provincias como resultado de la dinámica política de los representantes, pues llegaron a 26 universidades públicas y conformaron un amplio panorama de descentralización universitaria. Ello determinó que no hubiera una desconcentración de la histórica Universidad Central del Ecuador (UCE), localizada en la capital, Quito. Igualmente se produjeron dinámicas internas y externas a esta universidad que impulsaron su desconcentración por medio de sedes y ofertas de educación a distancia. Este fue el caso de la creación de la sede de una de sus facultades en Chimborazo, que por decreto legislativo pasó a desprenderse de la UCE y constituyó la base de la Universidad Nacional de Chimborazo. Sin embargo, el modelo de regionalización carece de fuerte empoderamiento ya que estas universidades son regionales exclusivamente en su localización pues su adscripción presupuestaria y de regulación

15 La Nación (30 de octubre de 2015). Eliminan el examen de ingreso para las universidades. La Nación. Disponible en: http://www.lanacion.com.ar/1841193-eliminan-el-examen-de-ingreso-para-las-universidades 
es nacional más allá de que hayan asumido el nombre de universidades nacionales o estatales de un lugar o provincia particular.

La regionalización con subsedes y regionales muestra los distintos niveles de calidad entre ellas y la sede central. La evaluación realizada por el Consejo Nacional de Evaluación y Acreditación, CONEA, desde 2009 a todas las universidades como resultado del Mandato Constitucional 14 que obligó a ese proceso, mostró las debilidades de las dos únicas extensiones existentes de la UCE localizadas en Galápagos (Facultad de Biología) y en San Francisco (Facultad de Filosofía), y derivó en su cierre por no cumplir los mínimos requeridos. Posteriormente, el Consejo de Evaluación, Acreditación y Aseguramiento de la Calidad de la Educación Superior, CEAACES, nuevo órgano de acreditación, cerró 44 de las 88 sedes regionales de las universidades por no cumplir los estándares de calidad. La lógica de regionalización cambió desde la aprobación de la Ley 298 de Educación Superior del año 2010, que dispuso que la creación de universidades requiere informes favorables del Consejo de Educación Superior (CES) y del Consejo de Evaluación, Acreditación y Aseguramiento de la Calidad de la Educación Superior (CEAACES), lo cual ha limitado las dinámicas de regionalización asociadas directamente a las luchas políticas y los empoderamientos regionales para pasar a estar sujetas a mayores niveles de control. Sin embargo, al tiempo, se ha impulsado una nueva política de regionalización mediante la creación de cuatro universidades "emblemáticas" especializadas orientadas a alta calidad y con fuertes recursos presupuestales localizadas en el interior del país.

\section{d. México}

En México, la diferenciación y regionalización mediante la creación de nuevas instituciones terciarias ha sido la característica dominante de la expansión de la cobertura universitaria desde muy temprano con la continua creación de universidades estatales asociada a las características federales de la Constitución y a la dinámica política (Martínez, 2002). La desconcentración por medio de sedes fue una dinámica reducida y acotada en general a las universidades de los Estados facilitada por el carácter federal de la Constitución y la diferenciación entre Universidades Federales o Nacionales y Universidades Estatales. La primera universidad de un Estado fue fundada en 1917 y para 1991 ya los 32 estados de la federación y el distrito federal tenían al menos una universidad estatal.

En los últimos años, esta política se mantuvo y se amplió la regionalización y a la vez la diferenciación institucional. Durante la presidencia de Felipe Calderón (2006-2012), se crearon 140 nuevas instituciones de educación superior consistentes en 43 nuevas universidades tecnológicas, 34 universidades politécnicas, 23 institutos tecnológicos estatales, 22 institutos tecnológicos federales, 13 universidades públicas estatales, federales o interculturales y 5 centros regionales de formación docente. Además, se crearon 96 campus o extensiones de instituciones terciarias existentes. Entre ellos es de destacar la creación de universidades virtuales de los Estados (Guanajuato, Michoacán, Distrito Federal, Veracruz, etc.) y la creación de la Universidad Abierta y a Distancia de México (UnADM). Hubo una expansión más fuerte de universidades e instituciones de educación superior estatales. Entre ellas tecnológicas, pedagógicas, politécnicas, virtuales o presenciales, indígenas o multiculturales, todo lo cual contribuyó a una amplia diferenciación no solo institucional sino de modelos de regionalización, e impulsó una regionalización mayor.

Esta regionalización promovió y contribuyó a la consolidación a una mayor tipología que se expresó en nueve tipos de instituciones de educación superior dentro del subsistema público. Ello ha promovido un sistema más diferenciado y más complejo, y que ha creado una dinámica de aumento continuo de la competencia en los mercados universitarios. Ello - junto a otros estímulos - ha contribuido a la fragmentación y jerarquización institucional y a una mayor pertinencia de las instituciones, y tal vez, globalmente, a mejores niveles de calidad por la vía de la especialización de algunas instituciones. En este contexto de mayor diferenciación, algunas instituciones aumentan su grado de especialización en la investigación y el posgrado, en especial algunas de las históricas instituciones como la Universidad Nacional Autónoma de México, UNAM, el Instituto Politécnico Nacional, IPN, la Universidad de Guadalajara, la Benemérita Universidad Autónoma de Puebla, BUAP o la Universidad Autónoma de Nuevo León, UANL.

La universidad federal más reciente fue creada en 1972-73 (Universidad Autónoma Metropolitana, UAM). La expansión universitaria y terciaria dominantemente desde entonces se ha realizado con base en universidades estatales, con apoyo federal y diverso peso de los estados en el financiamiento y la fiscalización. En este proceso la universidad se ha estatizado y desfederalizado. Asumiendo los enfoques que asocian el empoderamiento de los actores locales a esta pertinencia, se podría sostener que - aun cuando se requeriría mayor investigación - esto ha impactado en la propia calidad de la enseñanza. En este escenario de mayor intensidad de la diferenciación y la regionalización, muchos estados han estructurado políticas de educación superior regional, a partir de diversidad de instituciones para crear aparatos de regulación cada vez más complejos. El marco constitucional de México faculta a los estados federales a otorgar el reconoci- 
miento a las instituciones (Reconocimiento de Validez Oficial de Estudios, RVOE). Esta expansión y diferenciación pública ha sido determinante para que la expansión privada en los últimos años se haya enlentecido e incluso estancado en algunas regiones, más allá de la existencia de múltiples nichos de demanda sin cubrir ${ }^{16}$.

Este modelo de diferenciación y regionalización constituye una política de Estado, y continuando con ella, en el período 2012-2018 se espera abrir 69 nuevas universidades y 30 nuevos campus o extensiones: 20 institutos tecnológicos, 19 universidades politécnicas, 22 tecnológicos, pero al tiempo se reiniciarán modelos nacionales mediante la creación de 4 nuevas universidades federales (artes, tercera edad, interculturales), pero se proyecta que sean financiadas diferenciadamente mediante un esquema de asociación pública-privada. Ellas se sumarán a las seis instituciones federales existentes (UNAM, IPN, UAM, Colegio de México, UPN y Universidad Agraria Antonio Narro) para alcanzar 10 instituciones bajo este modelo que puede replantear las características de la regionalización y alterar parte de la política tradicional en materia universitaria entre el gobierno federal y los gobiernos estatales.

Aunque la cobertura ha aumentado regionalmente, ella se distribuye en forma desigual. Si tomamos por caso el Estado de Jalisco, allí la matrícula superior aumentó en 4\% interanual entre 2006 (164.626 personas) y 2012 (211.662), es decir, 28\% de cobertura que está aún por debajo de la media nacional, que es de $32 \%$. Pero de los 39 municipios, mientras que Guadalajara tiene $42,7 \%$ de la matrícula que la sitúa en la media de América Latina que es 42, el municipio de Zapopan tiene 27\%, o sea, 5 puntos por debajo del promedio nacional y 15 por debajo del de la región.

\section{e. Paraguay}

En Paraguay, en 1989 al salir de la dictadura de Alfredo Stroessner (15 de agosto de 1954-3 de febrero de 1989) había una sola universidad pública (Universidad Nacional de Asunción, UNA), y ya para 2013 había 7 nuevas, todas ellas localizadas en el interior del país ${ }^{17}$. El modelo de regionalización se ha basado en la expansión de universidades de igual rango legal pero localizadas en un departamento en particular. La expansión institucional del sector público mediante su regionalización ha impulsado un aumento generalizado de la matrícula pública a escala regional. Sin embargo, mientras que el sector universitario público pasó de una universidad en 1991, a 6 en 1996 y 8 en 2008, el sector privado pasó de 4 en 1991, de 9 a 13 en 1996, 35 en 2008 y ha seguido creciendo. La expansión institucional privada fue mayor que la pública, y en tal sentido la matrícula privada aumentó hasta alcanzar 81\% de la cobertura en 2011 con 245.157 estudiantes. En este contexto de menos expansión, el sector público decreció su peso relativo en la cobertura total al pasar de $46 \%$ en 2005 , a $31 \%$ en 2008 y a $19 \%$ en 2011 , a pesar de que su matrícula aumentó de 45.700 en 2005, a 51.687 en 2008 y a 58.382 en 2011, con una tasa de $4,14 \%$ anual en ese período. Es probable también suponer un mayor nivel de calidad pública, dado el acceso selectivo y los mayores recursos de las

16 En 2013 hubo 308.000 registros de estudiantes rechazados en universidades públicas y hay además en números reales unos 100.000 mexicanos sin cupo.

17 Ellos son la Universidad Nacional del Caaguazú (2007) en Coronel Oviedo (84.000 habitantes), Universidad Nacional de Concepción (2007) (68.000 habitantes), Universidad Nacional de Villarrica (2007) (55.000 habitantes), Universidad Nacional de Itapúa (1996) (146.000 habitantes), Universidad Nacional del Pilar (1994) (32.000 habitantes), Universidad Nacional del Este (en Ciudad del Este) (1993) (396.000 habitantes) y Universidad Nacional de Canindeyú (2010) (53.000 habitantes). 
universidades que han ido haciendo una regionalización de mayor nivel de calidad que las múltiples subsedes privadas.

Sin esta expansión institucional pública, la incidencia privada habría sido aún más alta (MEC, 2012). Para poder mantener el peso público, la expansión debería haber tenido un mayor nivel de expansión y cobertura en los 17 departamentos del país. La regionalización ha sido en tal sentido limitada y escasa, en relación con la demanda e incluso, no todos los departamentos tienen universidades. En cuanto a los municipios, la situación es de mayor debilidad en el sector público, aunque se constata un aumento de sedes en los municipios por las nuevas universidades públicas en los departamentos, más allá de que allí el sector privado ha expandido sus ofertas. La regionalización actual está avanzando hacia la creación de sedes en los municipios, en el tercer nivel del estado por parte de las universidades de los departamentos, aun cuando 10 departamentos de los 17 del país carecen de universidades nacionales.

\section{f. Perú}

En Perú, la regionalización de la universidad pública ha sido una constante del modelo político y universitario, lo cual a la vez ha contribuido a la ausencia de escalas elevadas por parte de las universidades públicas a partir de múltiples sedes regionales como acompañamiento de la expansión de la cobertura del país. De 2001 a 2013, las personas de 15 y más años con educación superior pasaron de 398.400 a 1.120.500, con un incremento de la población con educación superior universitaria en 182,6\%, con un aumento interanual promedio de $9 \%$.

Esta expansión de la cobertura y del egreso estuvo asociada a la fuerte diferenciación y regionalización de la educación. Continuando con el proceso histórico de creación institucional en el marco de iniciativas de parlamentarios de las regiones en un contexto en que las universidades eran creadas por el Congreso, en los 26 departamentos y 195 provincias que tiene el país, entre 2000 y 2011, se crearon 21 universidades públicas ${ }^{18}$. Con ello se ha pasado de 29 a 51 universidades públicas. Esta expansión

18 Ellas son: Universidad Nacional Amazónica de Madre de Dios, Puerto Maldonado (Ley 27.297 de 5 de julio de 2000); Universidad Nacional Toribio Rodríguez de Mendoza, Amazonas Chachapoyas (Ley 27.347 de 18 de septiembre de 2000); Universidad Nacional Micaela Bastidas, Apurímac Abancay (Ley 27.348 de 22 de septiembre de 2000); Universidad Nacional Tecnológica del Cono Sur de Lima, Lima (Ley 27.413 de 1 de febrero de 2001); Universidad Nacional José María Arguedas, Andahuaylas Apurímac (Ley 28.372 de 29 de octubre de 2004); Universidad Nacional de Moquegua, Moquegua (Ley 28.520 de 12 de mayo de 2005); Universidad Nacional de Juliaca, Puno (Ley 29.074 de 24 de julio de 2007); Universidad Nacional de Jaén, Cajamarca (Ley 29.304 de 19 de diciembre de 2008); Universidad Nacional de Cañete, San Vicente de Cañete, Lima (Ley 29.488 de 22 de diciembre de 2009); Universidad Nacional Autónoma de Chota, Cajamarca (Ley 29.531 de 11 de mayo de 2010); Universidad Nacional de Barranca, Lima (Ley 29.553 de 06 de julio de 2010); Universidad Nacional de Frontera Sullana, Piura (Ley 29.568 de 05 de agosto de 2010); Universidad Nacional Intercultural Fabiola Salazar Leguía, Bagua, Amazonas (Ley 29.614 de 17 de noviembre de 2010); Universidad Nacional Intercultural de la Selva Central Juan Santos Atahualpa, La Merced, Satipo, Junín (Ley 29.616 de 18 de noviembre de 2010); Universidad Nacional Intercultural de QuiIlabamba, Cusco (Ley 29.620 de 30 de noviembre de 2010); Universidad Nacional Autónoma de Alto Amazonas-Yurimaguas, Loreto (Ley 29.649 de 10 de enero de 2011); Universidad Nacional Autónoma Altoandina de Tarma, Junín (Ley 29.652 de 13 de enero de 2011); Universidad Nacional Autónoma de Huanta, Ayacucho (Ley 29.658 de 27 de enero de 2011); Universidad Nacional Tecnológica de San Juan de Lurigancho, Lima (Ley 29.659 de 27 de enero de 2011); Universidad Autónoma Municipal de Los Olivos, Lima (Ley 29.668 de 09 de marzo de 2011); Universidad Nacional Autónoma de Tayacaja Daniel Hernández, Morillo Pampas, Huancavelica (Ley 29.716 de 22 de junio de 2011); Universidad Nacional Ciro Alegría, Huamachuco, Sánchez Carrión, La Libertad (Ley 29.756 de 27 de julio de 2011). Asamblea Nacional de Rectores, ANR (2011). Datos estadísticos universitarios. Lima. Disponible en: http://censos.inei.gob.pe/cenaun/redatam_inei/doc/ESTADISTICA_UNIVERSITARIAS.pdf 
institucional permitió el aumento de la matrícula pública en términos absolutos, pero su crecimiento fue menor que la expansión del sector privado y no alteró la tendencia al decrecimiento relativo de la matrícula pública en Perú que para 2012 se había reducido a $36,7 \%$ con un total de 315.884 estudiantes desde 2005 cuando era de 281.374 (ANR). En el mismo período, la población de estudiantes de universidades privadas casi se duplicó al pasar de 277.906 a 546.409, pues han utilizado más ampliamente la figura de filiales y de la educación a distancia para cubrir las demandas. El modelo de expansión de sedes y de educación a distancia del sector privado fue más vigoroso y permitió aumentar en forma relativamente mayor su matrícula frente al sector público.

Hubo una fuerte regionalización de las universidades desde la capital que ha creado grandes redes nacionales. Por ejemplo, la Universidad Alas Peruanas, UAP, fundada con 8.000 estudiantes en 2008, paso a 108.000 en 2015 siendo no solo la más grande del país, sino además la de más rápida expansión y regionalización con sedes en todo el territorio. La alta expansión de la creación de filiales había mostrado sus características caóticas y sin control de calidad (GICES, 2006). El estudio del Grupo de Iniciativas para la Calidad de la Educación Superior, GICES, detectó para la fecha "la existencia de 232 filiales que ofertan 429 programas académicos, 179 programas de complementación académica y 42 programas de postgrado, de las cuales solo un 7,8\% se constituyeron respetando la ley sobre la materia y cuya expansión respondía al interés de las universidades por extender sus servicios fuera de su territorio original, en la mayor parte de los casos, aparentemente por móviles empresariales". En Perú, la matrícula de grado en el sector público es selectiva en el acceso y gratuita, mientras en posgrado es de acceso arancelado, modalidad que se ha constituido en el mecanismo fundamental de aumento de los recursos de las universidades en un contexto de escaso crecimiento del aporte público.

La oferta de las filiales de universidades públicas se orienta además a cubrir la demanda de los egresados de institutos superiores pedagógicos bajo la forma de complementación académica en modalidades semipresenciales que constituyen para la universidad una fuente de captación de recursos directamente recaudados. En el caso de las privadas, la dinámica de expansión de las filiales en el interior tiende a estructurarse en el marco de franquicias y acuerdos con empresas locales en una dinámica altamente marcada por el carácter orientado al lucro de la oferta privada. Sin embargo, ello permitió el ingreso de inversionistas locales externas al sector que hicieron fuertes inversiones en infraestructura educativa en el país. Estas, al tiempo, se beneficiaron de las exoneraciones tributarias dispuestas en el Decreto 882 de 1996 de promoción de la inversión en educación. La regionalización estuvo asociada en este sentido a la movilización de inversiones locales muchas veces en instituciones nacionales. Ello se tradujo en un muy débil mecanismo de aseguramiento de la calidad de carácter corporativo entre las propias universidades.

En 2012, se aprobó la suspensión de la creación de nuevas universidades y filiales públicas o privadas por cinco años. Esta moratoria tuvo como objetivo el replanteamiento de las políticas de educación superior universitaria y marcó el fin de una etapa de expansión por medio de una regionalización mediante sedes del sector privado y de nuevas instituciones públicas y abrió una nueva dinámica de regionalización con un marco normativo más rígido para la creación de instituciones, filiales y programas.

En 2014, se aprobó la nueva ley de educación superior que limita fuertemente estas filiales y conducirá a un proceso de depuración. La cobertura pasará a estar supeditada a mayores estándares de calidad no corporativos al desaparecer la función del Consejo Nacional para la Autorización de Funcionamiento de Universidades, CONAFU y la Asamblea Nacional de Rectores, ANR y conformarse un nuevo organismo regulador gubernamental.

\section{g. Uruguay}

El monopolio universitario público en el país que se ha mantenido desde 1838 en manos de la Universidad de la República, UdelaR, y recién fue alterado en 2013 con la creación de la Universidad Tecnológica del Uruguay (UTEC). La política pública en educación superior en los últimos años ha estado centrada en la búsqueda de aumentar la cobertura en el interior del país y en las formas de la regionalización. En este contexto incluso se ha planteado la universitarización de la formación docente pública con alto peso en el interior del país.

Ha habido un fuerte debate político y académico en los últimos años buscando promover una diferenciación pública y la creación de nuevas universidades, en especial para cubrir el interior del país, ha sido el factor determinante a su vez de una nueva política de regionalización de la UdelaR mediante la creación de tres centros universitarios regionales: noroeste, noreste y este. Con ello se incrementó la cobertura de la educación universitaria pública en el interior del país. En el quinquenio 2007-2012, la UdelaR abrió 31 carreras nuevas en el interior, con un total de 101, a partir de 2014. El número de jóvenes que estudian en el interior en la UdelaR creció 65\% de 2007 a 2012: de 4.000 a 6.741 estudiantes. La capital del país donde está radicada la UdelaR tiene el 40\% de la población nacional y esta tiene 85.000 estudiantes (2012), lo cual indica el 
bajo porcentaje de cobertura regional en su matrícula nacional y a la vez las tensiones asociadas a las demandas insatisfechas de acceso en el interior.

\section{b. Venezuela}

La actual República Bolivariana de Venezuela tenía una regionalización pública con un importante peso de universidades e institutos universitarios. Esto representaba un avance en la cobertura universitaria regional en un proceso que permitió pasar de 1970, cuando la región capital concentraba 51\% de la cobertura, a 1980 cuando su incidencia bajó a 37\%, a 1990 cuando se redujo a 29\% y a 2000 cuando continuó su reducción y alcanzó 24,7\% de la cobertura total (Morles, Álvarez-Bedoya \& MedinaRubio, 2003). Esta fase de la regionalización del sistema universitario tenía su base en la Ley de Universidades de 1970 y el Reglamento Parcial de la Ley de Universidades de 1971 que creó la figura de Universidades Experimentales con un menor nivel de autonomía y con sistemas universitarios muy diversos de instituciones (Rojas, 2005). Ello estuvo acompañado de una alta expansión de instituciones terciarias públicas y en especial privadas, como el Instituto Universitario de Tecnología Industrial Rodolfo Loero Arismendi, IUTIRLA, que tenía el $45 \%$ de la matrícula terciaria privada fundamentalmente en el interior. En este sector, para 2001, la matrícula de las 232 sedes y extensiones de los institutos y colegios universitarios terciarios era el $42 \%$ de la cobertura de la educación superior, y de ellos solo 59 estaban localizados en la región capital (Tovar, 2005). El total de sedes y extensiones oficiales era de 61, 26\% del total. Entre las extensiones, el $88 \%$ era privado y el $77 \%$ de la matrícula de estos institutos terciarios era privado y fundamentalmente localizado en el interior del país.

Esta configuración del sistema universitario y de las dinámicas regionales se comenzó a alterar significativamente desde inicios de la década pasada, cuando se planteó una nueva estrategia pública que facilitó la expansión y estatización de la cobertura de educación superior mediante la municipalización universitaria expresada en la creación de aldeas universitarias, la transformación de los institutos y colegios universitarios en universidades politécnicas territoriales y la creación de nuevas universidades de alcance nacional. Ello facilitó la expansión masiva de la cobertura pública en el interior del país, a sectores de menos ingresos y a hombres trabajadores.

Desde 2000, esta nueva fase de la universidad pública se apoyó además en una limitación a la expansión privada y a las propias universidades autónomas tradicionales (Rama, 2012a) y se basó en la conformación de un nuevo sector público, más regionalizado y más dependiente del gobierno, con menores controles de calidad y que implicó la creación de 20 nuevas universidades entre 1999 y $2011^{19}$. En parte fue una regionalización

19 Las universidades creadas fueron las siguientes siendo su matrícula para 2010: 1) Universidad Bolivariana de Venezuela (230.000); 2) Universidad Nacional Experimental Politécnica de la Fuerza Armada (UNEFA) (237.000), transformación del Instituto Universitario Politécnico de las Fuerzas Armadas Nacionales (IUPFAN) creado en 1999; 3) Universidad de las Artes (2.300 estudiantes); 4) Universidad Indígena del Estado Bolívar; 5) Universidad Indígena del Estado Amazonas (ambas con 810 alumnos; 6) Universidad Nacional Experimental del Sur del Lago de Maracaibo (6.000); 7) Universidad Deportiva del Sur (15.000 estudiantes); 8 a 13) Seis universidades politécnicas en los estados Aragua, Lara, Miranda, Táchira, Apure y Barinas; 14) Tecnológico del Estado Bolívar; 15) Universidad Politécnica (Territorio del Oeste, Cumaná, Estado Sucre); 16) Universidad Politécnica de Paria (Estado Sucre, surgida de la transformación del Instituto Universitario Jacinto Navarro); 17) Universidad Politécnica de Ejido (Estado Mérida); 18) Universidad Politécnica de Monagas (Estado Monagas); 19) Universidad Politécnica de Portuguesa (Estado de Portuguesa); 20) Universidad Militar Bolivariana (Decreto Presidencial 7.662, Gaceta Oficial 39.502, 2010). 
mediante la universitarización de la educación terciaria técnica derivada de la transformación de colegios e institutos universitarios públicos en una nueva figura como universidades politécnicas territoriales (UPT), dentro de la ley de universidades experimentales ${ }^{20}$.

Se crearon además las aldeas universitarias, espacios físicos bajo control ministerial donde todas las universidades ofrecen sus programas en una región particular y con una infraestructura compartida. También se crearon universidades especializadas como la Universidad del Cine y la Universidad Bolivariana de Venezuela que, junto a la dinamizada Universidad de las Fuerzas Armadas, alcanzaron a 467.000 estudiantes en 2010. Estas últimas se expandieron mediante decenas de sedes en el interior utilizando además cuarteles de las fuerzas armadas. En este contexto, la matrícula universitaria pasó de 785.285 estudiantes (1998) a 2.340 .000 (2011) con un alto nivel de regionalización de la cobertura.

La creación de nuevos accesos universitarios regionalizados se produjo mediante la figura de universidades nacionales experimentales creadas en la Ley de Universidades (1970) y se expresó en mayores niveles de especialización y de territorialización con universidades indígenas, temáticas artes, deportes, pedagógicas, militares- (UNEFA, Marítima) y politécnicas regionales y a la vez con un mayor control público, menores controles de calidad y menor nivel de autonomía. La Ley de Universidades permite un modelo altamente diferenciado de instituciones, sujeto a los estatutos de la institución autorizados por el gobierno nacional que no requirieron por ende una nueva tipología institucional.

La política de diferenciación continuó en 2012 y el Consejo Nacional de Universidades (CNU) aprobó la creación de la Universidad Politécnica Territorial de los Valles del Tuy y la Universidad Politécnica Territorial de Vargas $^{21}$. Igualmente, continuando con esta estrategia, en 2013 se crearon las universidades politécnicas territoriales de los Valles del Tuy y Altos Mirandinos Cecilio Acosta (Estado Miranda), y la José Antonio Anzoátegui (Estado Anzoátegui) que se suman a las 11 universidades territoriales creadas entre 2010 y 2012 (estados Aragua, Táchira, Miranda, Apure, Barinas, Lara, Portuguesa, Sucre, Mérida y Monagas). En 2014, se aprobó la creación de tres nuevas Universidades Territoriales: las de los Altos Mirandinos Cecilio Acosta, la Politécnica Territorial de los Valles del Tuy y la Territorial de Amazonas. Por medio de los decretos presidenciales 827, 828 y 829, de 17 de marzo de 2014, la Universidad Politécnica Territorial de los Altos Mirandinos Cecilio Acosta surgió de la transformación del Colegio Universitario de Los Teques Cecilio Acosta, para atender las carreras y programas que este ejecutaba. Finalmente, en octubre de 2014, se creó la Universidad de las Ciencias de la Salud por Decreto Presidencial número 1.317. Esta universidad está localizada en Caracas y tiene como sede administrativa el edificio anexo de la Maternidad Concepción Palacios, pero dispondría de los espacios académicos compartidos ubicados en las aldeas universitarias de Misión Sucre, los módulos y aulas de Medicina Integral Comunitaria, los Comités Académicos Bolivarianos Estadales de Salud (Cabes), los Comités Académicos Bolivarianos Locales de Salud (Cablos), la sede de la Escuela Latinoamericana de Medicina Dr. Salvador Allende, el Instituto de Altos

20 Tal proceso ya tuvo sus antecedentes en la creación de la Universidad Nacional Experimental Politécnica Antonio José de Sucre en Barquisimeto que se creó como transformación de los Institutos Politécnicos de Valencia, Caracas y Puerto Ordaz, y la Universidad Nacional Experimental Libertador (Pedagógica) que se creó a partir de la integración y transformación de diversos institutos pedagógicos de todo el país.

21 Gaceta Oficial 40.292,12 de noviembre de 2012. 
Estudios Arnoldo Gabaldón y los establecimientos pertenecientes al Sistema Público Nacional de Salud, con lo cual se estructura como una oferta regional en el sistema público de salud siguiendo el modelo cubano.

La política de expansión se paralizó en 2015 con la caída de los precios petroleros, pero la universitarización podría continuar como desconcentración, ya que al tiempo ella ha estado acompañada por una expansión de la cobertura con formas de desconcentración mediante la autorización de sedes de unas pocas universidades de carácter nacional, como la Universidad Nacional Experimental Simón Rodríguez (UNESR), la Universidad Militar Bolivariana y la Universidad Bolivariana, que cubren ampliamente el territorio nacional con una gran cantidad de sedes. De hecho, la UNESR tiene una dinámica crecientemente de funcionamiento a distancia, como la tradicional Universidad Nacional Abierta (UNA). Las universidades territoriales como nueva categoría buscan remediar las causas estructurales de los desequilibrios sociales y educativos regionales y constituyen un modelo de pertinencia curricular, de articulación local y a la vez de regionalización de la educación superior con un alto control desde el Ministerio del Poder Popular para Educación Universitaria, Ciencia y Tecnología.

Sin embargo, esta política de expansión universitaria y de regionalización no está correlacionada con cambios de la estructura productiva y mayor demanda de empleo profesional y técnico, sino más con variables políticas y de demanda individual de becas en un contexto de muy fuerte competencia y caída en los mercados profesionales, de caída del empleo privado y de una fuga masiva de capital humano, junto a un aumento enorme del empleo público.

\section{La regionalización como actividad central programada desde el Estado}

Colombia promovió en la década pasada una nueva modalidad de regionalización universitaria, mediante una política de Estado orientada a dar condiciones de acceso y permanencia a múltiples universidades, mediante la creación de sedes donde conciertan diversas instituciones del país, los ámbitos territoriales, las universidades y otros posibles actores regionales. El objetivo de facilitar el acceso a la educación superior a comunidades marginadas y alejadas de los centros urbanos se expresó en la creación de Centros Regionales de Educación Superior (CERES) en regiones donde no había oferta educativa. Son unidades físicas y administrativas cuya gestión puede ser pública o privada, y donde se ofrece y se apoya la oferta educativa local por parte de las instituciones nacionales. Mediante estos centros, las universidades reciben apoyos administrativos para soportar sus programas educativos locales tanto presenciales como semipresenciales o a distancia en función del propio registro calificado de esos programas.

Los CERES están dotados de infraestructura tecnológica de información y comunicación, mínimo de un aula virtual con 15 computadores, excelente conectividad y mecanismos de acceso a bibliotecas, prácticas de laboratorios y talleres según lo requiera el programa. Cuentan con un soporte académico y administrativo de una institución de educación superior "operadora" que apoya a las instituciones de educación superior que ofrecen programas a la comunidad desde tales centros.

El alcance de este modelo de regionalización sistémico compartido es importante conceptualmente pero es limitado en matrícula pues para 2012 el país contaba con 176 CERES distribuidos en 31 departamentos, con 30.948 estudiantes y que representaban apenas el 1,7\% de la matrícula universitaria total de grado que fue de 1.841 .282 estudiantes. Para algunas instituciones, este modelo ha sido sin embargo altamente útil. 
La Corporación Universitaria Minuto de Dios, UNIMINUTO, por ejemplo, aumentó su cobertura y regionalizó su oferta en forma significativa mediante la gestión de 29 CERES, con 13.563 estudiantes matriculados (Vélez, 2012). Los CERES son exclusivamente de docencia y no de investigación, a diferencia de otros centros de educación superior donde el docente debe soportar parte de su labor en la investigación, con lo cual esta regionalización implica un cambio del modelo universitario tradicional, al centrarse solo en las funciones de docencia. En tal sentido, pueden ser vistos como base de una regionalización de inferior calidad y a la vez más soportados en una mayor pertinencia, articulación y empoderamiento local.

También hay un cambio social de la matrícula pues los estudiantes de los CERES en su mayoría son provenientes de los estratos socioeconómicos 1 y 2 , con dificultades económicas y baja calidad formativa. Al menos, el $40 \%$ de los fondos que reciben los CERES proviene de recursos diferentes a las matrículas, resultado del apoyo de los miembros de la alianza estratégica conformada por entes públicos, privados, productivos, educativos y del sector social, y en la cual deben participar al menos el gobierno departamental y local, el sector productivo, las Instituciones de Educación Superior que ofrecen los programas y la IES operadora del CERES (CERES, 2012).

El modelo de aldeas universitarias de Venezuela tiene fuertes similitudes con los CERES, pero las Aldeas son exclusivamente para soportar una oferta terciaria pública.

\section{La regionalización por medio de la educación a distancia}

\section{a. El modelo semipresencial}

La educación a distancia constituye un modelo de enseñanza que implica un cambio en el acceso y permite una lógica de alta regionalización. Esta educación a distancia se realiza mediante sedes o polos en los cuales se desarrollan algunas de las actividades académicas presenciales o de apoyo administrativo, constituye una de las bases de un modelo particular de regionalización de la educación superior y cuya dimensión es cada vez más elevada en varios países como México, Argentina, Brasil, Perú, Costa Rica, Ecuador y Honduras con miles de polos y centros de apoyo. Esto ha permitido elevadas escalas por parte de las universidades que ofertan bajo estas modalidades. En Brasil, por ejemplo, el Centro Universitário Internacional, UNINTER, con sede en Curitiba tiene 140.000 estudiantes a distancia en 453 polos distribuidos en todo el país. Brasil tiene 1,1 millones de alumnos a distancia que representan el $15,85 \%$ de la cobertura total de la educación superior en 2012, 5.363 sedes y polos en todo el país de apoyo a la educación a distancia sobre estándares altamente elevados (Presse \& Nonato, 2014). La cobertura de la educación a distancia en Brasil ha sido tradicionalmente privada, hasta cuando por Decreto 5.800 (2006) se creó la Universidad Aberta do Brasil (UAB) que fue definida por el gobierno de entonces como de "interiorización de la educación superior" y planteada como el mecanismo para llevar educación superior dentro del continente y lejos de las grandes ciudades cercanas a las costas (Torres \& Vianney, 2008).

El modelo semipresencial de oferta educativa a distancia caracteriza la mayoría de los países de la región. Así, Brasil, Argentina, Uruguay, Perú, Costa Rica o República Dominicana imponen un modelo de oferta de educación a distancia que obliga a la apertura de sedes o polos para realizar en ellos las actividades presenciales o los tiempos presenciales que sus normas determinan. En este modelo, la oferta a distancia está obligada a mantener polos o centros con diversas exigencias que imponen una dinámica con actividades regionalizadas, pero en general sus contenidos no tienen pertinencia local. Estos modelos semipresenciales promueven diversidad de estructuras, alianzas y articulaciones regionales, para viabilizar la oferta en cada sitio y darle piso al acceso universitario.

En la región, el crecimiento de la educación a distancia constituye un relativo indicador de la regionalización de la educación superior pues es una modalidad educativa que se acerca a las personas, a diferencia del modelo presencial, que más allá de su localización, se caracteriza por ser un servicio educativo que impone el traslado de las personas. Su crecimiento elevado muestra su eficacia como modelo de regionalización. En Brasil, por ejemplo, en 2012 mientras que la cobertura de la educación a distancia se incrementó en $12 \%$, ese guarismo fue de solo $2,3 \%$ en la educación presencial. Ello marca que uno de los impulsos más importantes de la regionalización de la educación superior en la región proviene de la educación a distancia. En Ecuador, la Universidad Técnica Particular de Loja (UTPL) alcanzó 103 sedes, la Universidad Nacional Abierta (UNA) de Venezuela, 72 sedes; la Universidad Nacional Abierta y a Distancia (UNAD) de Colombia, 60; la UNED de Costa Rica, 38. Aunque el grado de empoderamiento académico de los programas es escaso, se generan contrataciones docentes y administrativas y las sedes en distinta proporción se articulan a los procesos locales y muchas veces donde se obligan pasantías y prácticas ellas se hacen localmente.

Se produce también un fuerte empoderamiento local pues muchas de las instituciones de educación superior a distancia se han gestado en ciudades pequeñas, y su expansión ha sido solo posible por la nacionalización, descentralización o regionalización 
de sus ofertas. Tal situación ha sido la dominante en América Latina. La Universidad Siglo XXI (Córdoba, Argentina), la Universidad Católica de Salta (Argentina), la Universidad de Bucaramanga (Colombia), la Universidad Católica de los Ángeles de Chimbote (ULAde$\mathrm{CH}$ ) (Chimbote, Perú), la Universidad Nuestro Señor de Sipán (Lambayeque, Perú), la Universidad Técnica Particular de Loja (Loja, Ecuador), el Tecnológico de Monterrey (Monterrey, México), la Universidad Abierta para Adultos (UAPA) (Santiago de los Caballeros, República Dominicana), la Universidad Belloso Chacín (Zulia, Venezuela) o la Universidad del Norte de Paraná (UNOPAR) y UNINTER (Curitiba, Brasil) y Universidade do Sul de Santa Catarina, UNISUL (Florianópolis, Brasil) son todas universidades privadas gestadas en el interior de una región que al no encontrar viabilidad para su expansión en sus propias regiones debido a la estrechez de los mercados, impulsaron nuevas lógicas de oferta mediante la educación a distancia y la nacionalización de sus coberturas con una amplia regionalización nacional. Ellas están entre las universidades a distancia privadas más grandes de la región y cuyas dinámicas educativas se iniciaron en regiones menores y en algunos casos, muy pequeñas.

Este modelo en la región se inició con la creación en los 70 y 80 de universidades públicas a distancia localizadas en las capitales de los países como la UNED (Costa Rica), UNAD (Colombia), UNA (Venezuela) que impulsaron el ingreso y la regionalización con múltiples sedes distribuidas nacionalmente, programas nacionales y materiales de apoyo como recursos instruccionales y sobre un modelo de enseñanza semipresencial. Esta regionalización universitaria tuvo posteriormente, en forma cada vez más importante en cobertura, sus expresiones privadas desde los 90 como UTPL (Ecuador); Universidad Católica de Salta, UCS (Argentina), UNOPAR (Brasil), TEC (México) que fueron sus primeras expresiones privadas. En la década pasada con la virtualización de las interacciones en plataformas digitales de aprendizaje se han desarrollado nuevos impulsos que han facilitado una fuerte expansión de estas modalidades en casi todos los países de la región. Múltiples universidades públicas y privadas como la UNAM (México), UNAH (Honduras), Universidad de Guadalajara (México), Universidad de Quilmes (Argentina) o privadas como ULADECH y UAP (Perú), Universidad Siglo XXI (Argentina) entre otras, han expandido sistemáticamente estas ofertas mediante multimodalidades que articulan componentes virtuales y semipresenciales con alta cantidad de sedes (Rama, 2012a). Este modelo ha dado alta regionalización, alta cobertura y formación de capital humano con menores niveles de empoderamiento de los cuerpos académicos y de las comunidades y actualmente está tendiendo su vigorización con ofertas públicas como la Universidad Aberta do Brasil y la Universidad Abierta y a Distancia de México con significativos niveles de crecimiento y de regionalización. Esta presencia local no se basa en sedes propias, sino en múltiples alianzas con instituciones académicas u otras públicas locales. Ello tiende a conformar un modelo regional en red de educación superior a distancia (Rama, 2015b).

La regionalización ha sido vista tradicionalmente bajo un doble paradigma de traslado de la capital hacia el interior (desconcentración) o de instalación local por parte de IES (descentralización). Con la educación a distancia, este paradigma se reestructura y se produce una expansión notable de sedes desde el propio interior de los países y se democratiza el acceso en las regiones. Las elevadas escalas además permiten precios reducidos y, por ende, mayores niveles de demanda. Muchas de las instituciones a distancia a su vez, incluyen docentes virtuales que son del interior de los países, pues los niveles salariales en el interior son menores.

\section{b. El modelo virtual}

La educación a distancia está cambiando radicalmente el enfoque de la regionalización con la virtualización y la habilitación de modelos 100\% virtuales pues estos no utilizan sedes o espacios físicos para algunos de los momentos educativos. Esta modalidad de acceso ha sido habilitada en México, Colombia y Puerto Rico con sus propios requerimientos, sin obligatoriedad de asistencia presencial. La expansión de la virtualización y la aparición de universidades totalmente virtuales y con ello el abandono del modelo tradicional semipresencial están cambiando el enfoque de la regionalización y de los aspectos de empoderamiento y de conformación de comunidades académicas locales. Este modelo de universidad red comienza a conformar dinámicas más confusas de regionalización. Los docentes y los estudiantes conviven en la red sin una localización significativa en el proceso de enseñanza. En México, los gobiernos estatales del Distrito Federal, Michoacán y Guanajuato han creado universidades $100 \%$ virtuales. Sin embargo, algunas de estas instituciones virtuales mantienen espacios físicos para facilitar la relación con los estudiantes con miras a obtener mayor fidelidad y reducir la deserción o para mayor fiabilidad y control de las evaluaciones presenciales. Tales son los casos de la Universidad Virtual de Guanajuato (pública) en México que tiene locales con computadoras en muchos municipios del Estado para que los estudiantes puedan acceder a las plataformas o el TEC Virtual (privada) (Monterrey, México) que lo impone para las evaluaciones, más allá de que sus autorizaciones no requieren esas interacciones presenciales. Con la virtualización, el proceso educativo es multidireccional en las plataformas, lo cual facilita a su vez 
dinámicas transregionales o transfronterizas con creciente presencia internacional también. A la fecha solo hay ofertas de enseñanza universitaria virtual en grado y posgrado en México, Honduras, El Salvador, Ecuador y Colombia, y exclusivamente en posgrado en Venezuela y Argentina. Estos modelos en red constituyen nuevas formas de regionalización con bajo empoderamiento, pero a la vez tienden a un uso muy elevado de docentes dispersos por los territorios.

\section{La regionalización como municipalización}

La municipalización de la educación superior, centrada en la oferta de servicios en todos los municipios de los países, es uno de los ejes de modelos de políticas de regionalización contemporáneas, fundamentalmente en Cuba y Venezuela. Cuba muestra una política continua de expansión institucional y de regionalización de la educación superior pública con dos fases muy marcadas. Desde la Revolución, cuando había una sola universidad en el país, se crearon universidades públicas monopólicas en cada una de las 14 provincias del país, dotadas de mecanismos selectivos de acceso asociados a los empleos públicos garantizados para sus futuros egresados. Con la crisis del campo socialista en los años 90, la matrícula cayó a la mitad y posteriormente se gestó un cambio en el modelo universitario y una masificación no asociada al empleo y orientada a la formación técnica de los trabajadores mediante estudios terciarios bajo un formato de municipalización gestionado desde cada una de las universidades provinciales. Fueron ofertas terciarias inicialmente, aunque hoy incluyen ofertas universitarias, expresadas en una desconcentración en las empresas, cooperativas y escuelas de los 168 municipios del país, en los cuales la enseñanza se realiza en estrecha relación entre la teoría y la práctica de las actividades académicas mayoritariamente en el mismo lugar de trabajo.

La regionalización como municipalización se centra en el tercer nivel de administración territorial y política del Estado, e incluye un nuevo enfoque de sedes, pedagogías y niveles. Con este formato de regionalización ordenado y estatal, Cuba alcanza la mayor cobertura de la región al soportarse en diversidad de sedes de trabajo. Tal es también el enfoque que promueve Venezuela por medio de las aldeas universitarias con miras a ofertar y tener un pie institucional en cada uno de los 335 municipios del país. Lo determinante en el modelo de "municipalización" cubano fue el carácter de estudios no universitarios, no de tiempo completo, de horarios nocturnos y que tampoco otorgan un empleo en el Estado, sino que es de formación a los que están trabajando y gratuito. En muchos casos, el estudio es obligatorio para las personas que trabajan, no se realiza sobre infraestructuras educativas sino sobre sedes de empresas, escuelas, cooperativas, organismos públicos, etc.

Igualmente, en Cuba, se continuó el modelo tradicional de regionalización y en 2011, cuando se creó la provincia de Artemisa (por división de la antigua provincia de La Habana en las actuales de Artemisa y Mayabeque) se creó en 2012 la Universidad de Artemisa, adscrita como todas al Ministerio de Educación Superior, mediante la fusión del Centro Universitario Municipal, la antigua filial regional occidental de la Universidad de las Ciencias Informáticas (UCI) y el antiguo Instituto Superior Pedagógico Rubén Martínez Villena. Las sedes pasaron a unificarse para constituir una nueva universidad, siguiendo el formato tradicional en muchos países del pasaje de sedes a universidades independientes como hemos analizado.

La regionalización como resultado de la expansión privada

El ámbito de la educación superior privada varía ampliamente en América Latina en lo atinente al grado de regionalización. Mientras que en la mayor parte de los países la educación privada nació con la primera universidad católica en la capital de los países en la segunda mitad del siglo XX, en Brasil, la universidad privada nace con fuerte sesgo regional con la Constitución de 1891 que descentralizó la educación superior que era exclusiva del poder central, al delegar la autorización en los gobiernos estatales, los cuales comenzaron a autorizar la creación de universidades privadas incluso antes que se gestaran las públicas (Sampaio, 2014). Ello le otorgó siempre un peso mayor y un superior nivel de regionalización, aunque la presencia actual en las grandes ciudades es el eje dominante de la alta incidencia de la matrícula privada.

En Brasil, la vocación centralista ha sido vista como una herencia del pasado colonial, imperial y también de la República, período en el cual siempre el "Estado como organización buscó centralizar como forma de ejercicio de su dominio" (Charfic, 2009). Esto determinó que no hubiera universidades en la época colonial ni en la época imperial. La centralización se incrementó durante el período populista del Estado Novo (1889-1937) cuando se elaboró un conjunto de leyes centralistas y uniformadoras de la organización política, jurídica y administrativa, entre las cuales estaba la creación de universidades públicas. En este caso, la descentralización educativa fue el instrumento de la sociedad civil para escapar del Estado centralizador, que se expresó en instituciones privadas en el interior, sobre todo de escuelas y facultades aisladas. La evolución de las constituciones y de las leyes educativas marcó esas tensiones entre el espíritu centralizador y el impulso descentralizador de las fuerzas sociales de las regiones. En este marco, la expansión de las universidades privadas, las estatales y las municipales ha 
estado asociada a responder a demandas locales y a la búsqueda de empoderamientos contra la centralización política y educativa nacional.

Desde los 80, en la región, la educación privada ha tenido su fuerte expansión inicialmente en las capitales y ciudades mayores y ha promovido su incremento por medio de procesos de regionalización en los segundos niveles del Estado fundamentalmente e incluso en el tercer nivel de las estructuras de los Estados (los municipios), dependiendo de su tamaño, de las habilitaciones y de los estándares exigidos. En este sentido, la regionalización es el segundo momento de la expansión privada y está siendo la base de la constitución de grupos nacionales con mayores escalas y elevados niveles de concentración en toda la región. La expansión mediante modalidades de descentralización se articuló a redes por la vía de la compra (Brasil) o creadas con los mismos estándares por las instituciones nacionales (México) con los casos del TEC, la Universidad del Valle de México y la Universidad Anahuac con amplias redes nacionales. Ello contribuyó a su constitución como grandes grupos nacionales y consolidó una lógica de un segmento de una educación superior altamente regionalizada en el sector privado en el marco de redes nacionales articuladas.

Este ha sido uno de los componentes que han permitido el aumento de la participación privada con un incremento importante de la matrícula en términos absolutos que se duplicó entre 2000 y 2010 y alcanzó 10.358.171 estudiantes, que representaban el 51,6\% de la cobertura. La regionalización fue la base para el crecimiento del sector privado y facilitó su crecimiento por concentración y aumento de escalas de las instituciones (Rama, 2012a). La conformación de grandes redes universitarias, en especial en Brasil, donde además participan inversores internacionales, ha cambiado la presencia de la universidad privada a escala regional. Ello ha sido más marcado donde hay un modelo de gestión por medio de sociedades anónimas que han permitido procesos de unificación de unidades institucionales vía compra, como en Perú, Panamá, Costa Rica, Brasil o México, entre otros países. En Brasil, entre 2007 y 2013 se adquirieron 110 instituciones de educación superior; la mayor parte de las compras se dio en el interior ${ }^{22}$.

Este escenario de regionalización se diferencia de la desconcentración porque funciona como integración en el grupo empresarial de instituciones existentes en las regiones, que se mantienen con sus propias sedes, marcas y autorizaciones de programas propios y que pasan a conformarse en nodos dentro de las redes de grandes universidades. En los otros casos, la expansión privada se realizó por las tradicionales formas de desconcentración mediante filiales y subsedes. Estas han dado un peso destacado a las modalidades semipresenciales. El peso de la educación a distancia en esta expansión y regionalización es significativo en Ecuador, Argentina, Ecuador, Brasil y Colombia. Los grupos nacionales privados también han sido motores de estos procesos en Bolivia, Chile, Colombia y México.

\section{La regionalización por medio de instituciones universitarias interculturales}

La expansión de la educación superior indígena e intercultural en América Latina está impulsando una regionalización de la educación superior en los sitios donde se localizan las comunidades indígenas de los países y las instituciones y los programas se localizan en esas zonas. Esta

22 En Brasil, el grupo Anhanguera adquirió 32 instituciones de educación superior localizadas en 32 ciudades, el grupo Kroton adquirió 19 instituciones en 28 ciudades; el grupo Estácio de Sá compró 18 en 15 ciudades y el Grupo Sistema Educacional Brasileiro, SEB, adquirió 13 IES en 12 ciudades (Cristina Helena de Almeida Carvalho, 2013, citada por Helena Sampaio, 2014). 
regionalización no refiere solo a una localización espacial, sino también a una estructura curricular y una orientación específica que hacen que estas instituciones y programas conformen una tipología y un subsector universitario diferenciado. Varias expresiones se han producido en la región en la última década, entre las cuales destacan las experiencias de México, Bolivia, Colombia y Nicaragua. En México, donde esos sectores representan el $12 \%$ de la población nacional, desde el gobierno de Vicente Fox (20002006), la educación intercultural indígena se ha expandido mediante la creación de 12 universidades interculturales y que al tiempo han creado un subsistema de educación superior que se expresó en la creación de la Asociación Nacional de Universidades Interculturales (ANUI) (Redacción El Sol de San Luis, 24 de octubre de 2014). Los ejes transversales de las universidades interculturales se apoyan en la enseñanza de las lenguas originarias; los estudiantes eligen una de ellas para aprender o fortalecer —en el caso de ser hablantes - la vinculación con sus comunidades de origen y reforzar el acercamiento con la realidad en la que viven las comunidades y la diversidad intercultural con una fuerte articulación a sus comunidades (Síntesis Vox, s.f.). Ellas marcan una regionalización bajo un modelo educativo diferenciado y segmentado socialmente que, a la vez, conforma un nuevo subsistema universitario con una nueva tipología de instituciones. Igualmente, el Estado ha trazado políticas propias para la Red de Universidades Interculturales, REDUI, mediante acciones de la Coordinación General de Educación Intercultural Bilingüe que ha impulsado la creación de estas universidades.

Esta regionalización universitaria se aprecia también en forma destacada como política pública en Bolivia. En este país, la regionalización de la educación superior se desarrolló a partir de la instalación de universidades autónomas públicas con igual estatus más allá de su tamaño en cada uno de sus 9 departamentos como derivación de una lógica nacional de equilibrio político entre las distintas regiones ${ }^{23}$. Estas universidades son autónomas del gobierno central, del cual reciben los fondos, y del departamental, y se coordinan con estándares comunes en el marco del Comité Ejecutivo de la Universidad Boliviana (CEUB) y cada una solo puede actuar y ofrecer servicios educativos en su departamento. Solo la Universidad Militar actúa en todo el territorio nacional, pero sus ofertas no tienen régimen de competencia y su presupuesto proviene de otra fuente. Igualmente, coordina sus servicios y cumple los estándares del CEUB. La Universidad Católica Boliviana (UCB), la primera universidad privada del país, es también miembro del CEUB, pero tiene cobertura en todo el país con cuatro sedes.

En los últimos años, la regionalización de la educación superior ha sido el eje de la diferenciación que además asocia un cambio en la orientación socioeducativa. En 1989, tras la firma de un convenio entre instituciones sociales de la ciudad de El Alto ( 960.000 habitantes y la de mayor crecimiento del país con alta población indígena migrante del altiplano) y la Universidad Mayor de San Andrés (UMSA, de La Paz), esta creó una sede como facultad técnica con tres carreras. A partir de entonces, hubo movilizaciones sociales y estudiantiles en busca de la instalación de una verdadera universidad que tuviera ofertas de licenciatura, que derivó, 11 años después, en 2000, en la creación de la Universidad Pública de El Alto (UPEA) (Bolivia, 4 de septiembre de 2000). Se preveía que la UPEA en sus primeros 5 años estuviese bajo tuición académica del CEUB y cumplido ese lapso, alcanzase la calidad institucional plena de universidad pública

23 En el departamento del Beni con una población de apenas 109.000 habitantes (2012) se creó la Universidad del Beni. 
autónoma para formar parte del CEUB, en el marco de lo dispuesto el artículo 185 de la Constitución Política del Estado de 1967, reformada en 2009 que establecía que las universidades son autónomas y con igual jerarquía.

La lucha social develó la discusión de los dos modelos tradicionales la regionalización: por un lado, la creación de una universidad en el mismo departamento y por el otro, una sede de la UMSA. Pero dada la presencia dominante de población indígena en El Alto y en un contexto de radicalización política, se dio un debate entre un modelo de regionalización como universidad indígena o un modelo de universidad tradicional autónoma como las que hay en cada departamento. La nueva institución era vista como la oportunidad para una universidad con un currículo, perfil y una estructura de poder y de orientación indigenista. Las modalidades de regionalización mediante una sede de la UMSA o de una universidad pero bajo la tuición del CEUB eran vistas como la expresión de un modelo tradicional de formación profesionalizante con fuerte raíz "colonial". La creación de la universidad planteó, más que un modelo de regionalización universitaria, un debate sobre el empoderamiento indígena y la búsqueda de mecanismos de ascenso político de los movimientos indígenas. Ello no solo mostraba el rol de la universidad en general y que como tal era reclamada por grupos marginados de las estructuras de ascenso social, sino que adelantó las discusiones posteriores sobre la "educación descolonizadora" (EABolivia, s.f.), que se expresó en la nueva Ley de Educación con la llegada del Movimiento al Socialismo, MAS y de Evo Morales al gobierno del país (Estado Plurinacional de Bolivia, Ministerio de Educación, 2010).

La existencia de este monopolio departamental de la oferta universitaria, y sobre todo de su financiamiento, llevó a la resistencia expresada en una demanda de nulidad ante los ámbitos judiciales por parte de la Universidad Mayor de San Andrés (UMSA) del departamento de la Paz, respecto a la creación de la Universidad de El Alto en el departamento de La Paz, donde la UMSA ostenta el monopolio constitucional. Ello solo fue subsanado cuando el estatus administrativo de El Alto pasó a ser especial y diferenciado.

El debate sobre regionalización — vía descentralización o desconcentración - impulsó una modalidad de diferenciación institucional mediante la regionalización indigenista. Esta se concretó con la asunción de Evo Morales a la presidencia, mediante la creación de tres universidades indígenas comunitarias interculturales productivas, correspondientes a las tres comunidades indígenas mayoritarias (aymara, quechua y guaraní) y localizadas en las regiones con más peso de estas comunidades. Estas instituciones además han establecido subsedes en el país en función de la localización de las diversas etnias y grupos indígenas objeto de su misión que no coinciden con las fronteras de los departamentos. Estas nuevas universidades indígenas rompieron el rígido modelo de regionalización con monopolios por parte de las 9 universidades autónomas en cada uno de los respectivos departamentos del país. Las nuevas universidades fueron creadas bajo un régimen especial y tuición del Ministerio de Educación y no son autónomas de acuerdo a lo establecido en la Constitución ${ }^{24}$. La formación se dispuso que fuera en la lengua de cada uno de los tres pueblos, con aprendizaje adicional de castellano y de un idioma extranjero, lo cual segmentó el estudiantado por su procedencia desde las comunidades indígenas.

Las tres casas superiores de estudio tienen como fundamento una educación descolonizadora, intracultural e intercultural, productiva, comunitaria y familiar; son universidades solo para los indígenas de esas comunidades, más allá de su localización; tienen un acceso selectivo e incluso los estudiantes son propuestos por las comunidades. La iniciativa obedeció "a la necesidad de crear otras opciones y oportunidades de estudio para sectores que históricamente fueron discriminados". Este modelo fue también criticado por sectores indígenas; Víctor Hugo Cárdenas, el exvicepresidente indígena (1993-1997), planteó que estas universidades son "la expresión de un discurso etnicista e ideologizado". El oficialismo ha considerado que estas universidades "recuperan los saberes de los pueblos indígenas y complementan la enseñanza con los saberes de otros pueblos" (Vaca, 13 de abril de 2009). La dimensión en términos de regionalización es, sin embargo, marginal: para 2014 se graduaron 121 profesionales y apenas había 2.300 estudiantes indígenas en las tres universidades (Opinion.com.bo, 2 de agosto de 2014).

El escenario público no ha sido el único ámbito de esta regionalización universitaria, sino que ha habido varias iniciativas privadas. Entre ellas es de destacar que luego de muchos años, el Consejo Regional Indígena del Cauca (CRIC) de Colombia logró la creación de la Universidad Autónoma Indígena Intercultural (UAIIN) como parte de su Sistema Educativo Propio (SEP) con miras a apoyar el 1,83\% de la población nacional que se considera indígena, consolidar su poder y ejercicio social en territorios en disputa política, detener la emigración para crear capacidades, reforzar el acervo cultural, proteger las lenguas y aumentar el escaso porcentaje de la población en edad estudiantil

24 El marco normativo fue dado por el Decreto Supremo 29.664, que dio nacimiento a la Universidad Indígena de Bolivia (Unibol), de manera conjunta: en Warisata (La Paz) nació la Universidad Indígena Aymara Tupac Katari; en Chimora, Cochabamba, se instaló la Universidad Indígena Quechua Casimiro Huanca y en KuruyukiChuquisaca, la Universidad Indígena Guaraní Apiaguaiki Tüpa. 
inserta en programas universitarios que en 2004 era de 0,6\% (Bolaños, Tattay \& Pancho, 2009).

Con ello se consolida un camino de educación superior intercultural desde la sociedad civil, ya existente por ejemplo en Nicaragua con la creación en 1990 de la Universidad de las Regiones Autónomas de la Costa Caribe Nicaragüense (URACCAN) como institución privada con financiamiento público orientada a la población costeña con sus particularidades socioeconómicas, políticas y culturales. Esta zona tiene una alta población negra y misquita. Con una matrícula actual de más de 7.000 estudiantes, la institución está regionalizada en las zonas de la costa con recintos universitarios y extensiones en Bluefields, Bilwi, Wasmpam, Las Minas, Siuna, Rosita, Bonanza, Waslala y Nueva Guinea ${ }^{25}$.

\section{Las universidades tecnológicas y politécnicas como escenario de la regionalización}

Desde los 90 y con más intensidad desde la década pasada, la región está asistiendo a un proceso de diferenciación institucional de la educación superior mediante la creación de universidades e instituciones tecnológicas y politécnicas, localizadas dominantemente en el interior de los países, acorde a nuevas particularidades en la inserción económica y en el perfil productivo de la región latinoamericana. Esta diferenciación tecnológica ha dado lugar a la creación de muy variadas instituciones, como universidades e instituciones tecnológicas, tecnológicos descentralizados u universidades politécnicas. Este proceso iniciado en algunos países levemente desde principios de los 90 , se ha ido dinamizando y generalizando en toda la región, más allá de sus especificidades nacionales. Esta diferenciación no se reduce a una expansión institucional terciaria con un perfil de ofertas tecnológicas, sino que cambia los ejes de la organización de los sistemas de educación superior tradicionalmente jerarquizados entre una formación profesional de nivel universitario y una formación técnica de nivel terciario; en la primera, el peso del currículo se apoya en lo teórico mientras que en la segunda lo dominante es lo práctico y una formación aplicada y terminal asociada a los oficios (Rama, 2015a).

Bajo el nuevo paradigma universitario en construcción, todo el sistema de educación superior se reestructura para crear un subsistema tecnológico universitario con fuerte acento regional por su mayor pertinencia laboral y enfoque por competencias a la par que el tradicional sistema universitario de enfoque profesional centrado en forma más dominante en las capitales o grandes ciudades y que, además, dota el sector tecnológico de estudios de posgrado, lo articula

25 http://www.uraccan.edu.ni/ a una formación técnica o tradicional en la educación media, permite una mayor movilidad horizontal vía créditos y se concibe de alta calidad incluyendo en algunos casos instituciones más orientadas a la investigación. Este proceso se está produciendo a escala regional con múltiples matices y entonaciones, derivados de las distintas restricciones y características, pero que en todas partes muestra el aumento de la diferenciación y complejidad de los sistemas universitarios, incorporando cambios en los paradigmas educativos, en las formas de gobierno, en las articulaciones regionales, en la localización de las instituciones y de sus ofertas y así mismo en las pertinencias educativas.

\section{La regionalización como modelo de calidad}

Ecuador tiene en curso una nueva política de regionalización pública orientada a la especialización académica, mediante nuevas instituciones que, a la vez, pretende alterar el paradigma de desigualdad de niveles de calidad y de recursos presupuestales entre el interior y la capital del país en lo que refiere a la regionalización y prestación de los servicios educativos públicos ${ }^{26}$. Ello se ha expresado en nuevas universidades públicas localizadas en el interior del país con una mayor dotación de recursos y de exigencias de calidad27 (La Hora Nacional, 5 de julio de 2013). Su objetivo es constituirse en referentes y estándares para otras universidades, facultades y carreras, e impulsar un cambio en el sistema y una nueva estratificación, al buscar colocarse en el nivel superior. Su gestación parte del supuesto de que la introducción de reformas es muy lenta en las universidades tradicionales y dada la resistencia a los cambios, es necesario crear nuevas universidades para impulsar el cambio. En este sentido, la regionalización busca imponer nuevos "proveedores educativos", pero locales, en el sistema universitario público; en este caso, universidades de investigación. El enfoque es, por ende, de regionalización universitaria pero agrega el carácter de su especialización disciplinaria y de mayores niveles de calidad al focalizarse en la investigación, más allá de que se espera que cada una de estas universidades cubrirá una población de entre 20.000 y 25.000 estudiantes $^{28}$. El presupuesto para las cuatro

26 La Secretaría Nacional de Educación, Ciencia y Tecnología (SENESCYT) envió el proyecto de ley de creación de estas instituciones al Legislativo en 2013.

27 Ellas son la Universidad Nacional de Educación (UNAE), la Universidad Regional Amazónica (Ikiam), la Universidad de las Artes (Uniartes) y la Universidad de Investigación Experimental Tecnológica (Yachay), las cuales fueron contempladas en la disposición transitoria décima quinta de la Ley Orgánica de Educación Superior (LOES) aprobada por la Asamblea en 2010 y aprobadas en 2013.

28 La Universidad Nacional de Educación se localiza en la parroquia Juan Loyola, de Azogues, Cañar en la capital; en el Litoral, en 
nuevas universidades (De las Artes, Yachay, Nacional de Educación e Ikiam) es elevado pues se dedicarán a profundizar en investigaciones ${ }^{29}$.

Estas cuatro universidades se suman a las 54 existentes en el momento, pero el objetivo es que gracias a los recursos y las calificaciones de sus equipos docentes ellas sean de categoría $A$, en la calificación estratificada que realiza el Consejo de Evaluación Acreditación y Aseguramiento de la Calidad de la Educación Superior (CEAACES) grupo en el que solo hay tres universidades de grado y dos de cuarto nivel.

\section{Conclusión}

Nueva dinámica de regionalización marcada por una mayor diversidad de modelos

En el presente artículo se buscó develar cómo en los últimos años se asiste a una nueva dinámica de regionalización de la educación superior en América Latina con una ampliación de las modalidades existentes y que con ella incluso se logra el ingreso de la oferta terciaria en los municipios, en el tercer nivel del Estado. Aunque en algunos países aún se carece de servicios en el segundo nivel de los Estados (regionalización), en otros se inician ofertas en el tercer nivel (municipalización). Esta dinámica ha sido la base del aumento de la cobertura pública y privada en estos años, al ir agotándose el potencial de crecimiento no vegetativo en las ciudades y en los quintiles de ingresos medios y altos. En términos de regionalización, esta fase se caracteriza por una mayor instalación de universidades públicas en las regiones y a la vez por una diversidad de modelos y formas de permitir la cobertura y el acceso en las regiones.

Las permanentes tensiones existentes en América Latina entre la capital y las regiones se han resuelto en los últimos años hacia un mayor peso de las regiones, en parte asociado a nuevos desarrollos económicos. La matrícula y las nuevas instituciones han sido una expresión de esas nuevas correlaciones de fuerzas y sociales en la región.

En este contexto se constatan múltiples procesos de regionalización tanto en las regiones como en los municipios con formas más amplias y diversas que superan el enfoque dual de desconcentración o descentralización para acceder a la educación superior. Ello muestra un panorama más complejo y diferenciado en el funcionamiento de los sistemas universitarios nacionales en los aspectos asociados a la regionalización y que constituye la base del aumento de la cobertura atendiendo a grupos sociales, nichos y campos disciplinarios.

Es un camino de diferenciación institucional que aumenta a medida que la oferta se regionaliza y es resultado de un mayor nivel de presiones económicas, sociales y políticas desde las regiones con lógicas políticas o de mercado para acceder a la instalación de universidades de los municipios, departamentos, estados, provincias o regiones, lo que se ha facilitado por la consolidación democrática en América Latina y un mayor empoderamiento de las regiones.

Guayaquil, se creó la Universidad de las Artes (Uniartes) y las otras instituciones se localizan en la región de la Amazonía en Napo, donde se edifica la Universidad Ikiam, cuyo eje académico será la investigación de la biodiversidad. La Universidad del Conocimiento se instaló en la provincia de Imbabura, en Yachay, la primera Ciudad del Conocimiento que tendrá como objetivo la investigación científica y la formación en nuevas industrias.

29 Para la construcción y financiamiento de estos centros superiores se aprobó destinar US\$1.100 millones entre 2013 y 2017. La dimensión es significativa si se piensa que, desde 2006 a 2013, la inversión total en Educación Superior ha sido de US\$7.348 millones. 
Esto también se ha facilitado por el desarrollo económico del interior de los países, pues a medida que aumenta la apertura externa de las economías, se reafirma el viejo eje primario exportador y de producción en las regiones, en un contexto de más altos precios de sus productos, pero con un mayor valor agregado y que requiere un trabajo más capacitado. Esto reclama un aumento de la cantidad de estudiantes y egresados de las regiones. Irrumpen así en el interior de los países nuevos modelos de crecimiento industrial y de servicio, con el concomitante aumento de demandas profesionales. Estos desarrollos están en la base del aumento de los recursos públicos y privados destinados a la educación superior en la última década.

Vista como proceso general, la regionalización en curso muestra una mayor propensión que en el pasado hacia la creación de instituciones, distinta tipología institucional y nuevas modalidades de acceso, frente al tradicional modelo de regionalización por sedes y subsedes, impulsadas autónomamente por las universidades.

Esta nueva regionalización universitaria en curso no es meramente una evolución interna de las universidades, ni una expresión de la competencia interinstitucional ante el sector privado o público, o un resultado mecánico de nuevas demandas políticas y sociales que exigen mayor presencia de ofertas públicas en sus regiones y plantean la creación de nuevas instituciones públicas. Estos elementos se dan junto a un cambio en las lógicas y dinámicas de los sistemas de educación superior para viabilizar esas demandas y nuevas realidades. En este escenario, la regionalización muestra una mayor entonación de lógicas descentralizadas con mayor diferenciación institucional frente a las tradicionales dinámicas desconcentradas como formas de cubrir las demandas de acceso.

En América Latina se advierte un cambio con sus matices y diferencias, en las formas de regionalización hacia un relativo detrimento de las formas tradicionales de desconcentración por sedes y filiales desde las universidades de las capitales, y una mayor incidencia en la creación directa de universidades, en especial porque la expansión de subsedes proviene de universidades localizadas en el segundo nivel que ofrecen sus servicios en municipios del nivel terciario de los Estados. Pero a la vez se aprecia el ingreso de nuevas formas de prestación de los servicios, como la educación a distancia, la existencia de campus con articulaciones de diversos oferentes como las aldeas universitarias de Venezuela o los CERES de Colombia, la formación tecnológica universitaria o la educación multicultural. En este contexto, se aprecia además un mayor control y limitación a la descentralización o desconcentración por el sector privado al aumentarse en general los requisitos públicos para la apertura de instituciones, sedes, subsedes o filiales en el interior, como en Ecuador, Perú, Brasil, Venezuela, Panamá, Uruguay y Bolivia.

La regionalización ha tendido a ser analizada desde el punto de vista de su impacto en el acceso, y con menos intensidad como un proceso de desarrollo universitario diferenciado entre modalidades de desconcentración y de descentralización con sus diversos grados y entonaciones. En este enfoque, se aprecia una mayor tendencia a formas de descentralización, con mayores niveles de autonomía y de empoderamiento frente a las tradicionales estructuras urbanas capitalinas. Ellas, sin duda, son las fuerzas que están contribuyendo al aumento generalizado de la cobertura en la región que para 2013 superó 43\% y que en el período 2000-2010 facilitó el aumento de 6,64\% interanual de la matrícula, el pasaje de una cobertura de $23,4 \%$ a $41 \%$ y de la matrícula absoluta de 11,269 millones a 
21,160 millones (UNESCO/UIS). Incluso permitió alterar la relación entre el crecimiento público y privado.

En este contexto, los análisis sobre el empoderamiento y la pertinencia se complejizan. La desconcentración por medio de sedes o la descentralización por medio de instituciones manifiestan diversidad de grados de autonomía, de estándares, de articulación local y regional y, por ende, de niveles de empoderamiento y muy seguramente en niveles de calidad. En tal sentido, las nuevas investigaciones deberían analizar cómo impacta el empoderamiento las localidades, la pertinencia de los programas y el desarrollo de redes académicas, económicas y sociales locales. Se sostiene que las capacidades y la construcción de capital social son la base del desarrollo (Putnam, 1993). Sin embargo, las actuales líneas de investigación muestran que la cobertura es menos importante en la creación de capacidades que la calidad de la enseñanza (Hanushek, 2011; Heredia, 2011). En tal sentido, inversamente cabe considerar que una dinámica de regionalización universitaria con bajo empoderamiento, que en general se asocia a procesos de desconcentración por medio de sedes como forma de la regionalización, limita la calidad en la construcción de capacidades pues reduce las articulaciones locales y favorece articulaciones a la sede central en las capitales, o incluso promueve enfoques academicistas de los programas con baja pertinencia local.

El proceso en curso parece contradictorio entre algunas de las diversas modalidades de la regionalización. Por ejemplo, aunque se constata un aumento de las universidades públicas, y también privadas, a escala regional también hay una expansión de la oferta de educación totalmente virtual sin apoyos locales presenciales, que amplía la formación de capital humano en cantidad y diversidad, muestra limitaciones en relación con la formación de capacidades de gestión y de empoderamiento académico y social a escala local. Inversamente, la creación de universidades locales presenciales puede aumentar el empoderamiento pero a la vez, por sus escalas y costos, tiende a una menor diferenciación de ofertas académicas. Por su parte, las ofertas por medio de sedes desconcentradas tienden a un escaso nivel de empoderamiento en términos de gestión y muchas veces, funcionan como simples terminales de un servicio educativo transregional nacional que lleva y trae docentes sin ninguna articulación local ni creación de capacidades locales. Estas requieren la conformación de redes locales, ofertas con pertinencia y niveles de investigación y de extensión para crear capital social local, crear empoderamiento y, también, junto a otras variables, una educación de calidad.

La pertinencia y el empoderamiento asociados a la calidad deberían ser objeto de estudios más profundos para identificar en este nuevo contexto de presencia e instituciones en los niveles locales, la relación entre cogobierno local con participación de múltiples actores, calidad de los procesos de enseñanza y desarrollo local. En este sentido, se considera que los enfoques sobre la regionalización de la educación superior —-más allá de su impacto en el acceso y el egreso- deben iluminar asociado a ese empoderamiento, el tema de la calidad en la construcción de las capacidades regionales como determinantes de un desarrollo armonioso, equilibrado y a la vez especializado a escala regional y nacional. Sin empoderamiento se torna complejo el hecho de que los programas locales puedan alcanzar una efectiva pertinencia, pero ello es apenas un prerrequisito para la calidad. Es condición necesaria, pero no suficiente.

Este es un proceso en curso, pero más allá del crecimiento de la regionalización, la municipalización y de la diferenciación institucional, en todos los países de la región aún hay fuertes desigualdades universitarias 
en los accesos, procesos, egresos, pertinencia y en especial en la calidad en detrimento de las ofertas en las regiones. En este sentido, la regionalización es una materia inconclusa y en construcción, incipiente, aun cuando se constata que en los últimos años tiene un empuje mayor, que adquiere una mayor complejización y diferenciación de modalidades y una propensión a dinámicas de descentralización y diferenciación institucional con el desarrollo de universidades regionales con mayor nivel de empoderamiento.

\section{Sobre los autores}

Claudio Rama es especialista en educación superior. Economista, máster en educación, doctor en educación, doctor en derecho y con cuatro posdoctorados. Investigador (Nivel II) del Sistema Nacional de Investigadores del Uruguay, SNI. Profesor - investigador de la Facultad de Ciencias de la Educación, Universidad de la Empresa (UDE) del Uruguay. Coordinador del Observatorio de la Educación Virtual en América Latina (OEA-Virtual Educa). Asesor del programa Prometeo del Consejo de Educación Superior (CES) de Ecuador.

Marcelo Cevallos es ingeniero agrónomo. Máster en biología vegetal y doctor en ciencias agrícolas. Profesor, Escuela Politécnica del Ejército (Ecuador). Miembro académico del Consejo de Educación Superior y Presidente de la Comisión de Universidades y Escuelas Politécnicas.

\section{Referencias}

Argentina, Ley 17.778, universidades provinciales, 12 de junio de 1968. Disponible en: http://www.coneau.gov.ar/archivos/546.pdf

Argentina, Ley 24.521, Ley de educación superior, 20 de julio de 1995. Disponible en: http://www.me.gov.ar/spu/legislacion/Ley_24_521/ ley_24_521.html

Bolaños, G.; Tattay, L. \& Pancho, A. (2009). Universidad Autónoma, Indígena e Intercultural (UAIIN): un proceso para fortalecer la educación propia y comunitaria en el marco de la interculturalidad (Colombia). En Daniel Mato (coord.). Instituciones interculturales de educación superior en América Latina. Procesos de construcción, logros, innovaciones y desafíos, 155-190. Caracas: Instituto Internacional de la UNESCO para la Educación Superior en América Latina y el Caribe, UNESCO-IESALC. Disponible en: www.iesalc.unesco.org.ve/ dmdocuments/colombiauniautonoma2.pdf

Bolivia (4 de septiembre de 2000). Creación de la Universidad Pública de El Alto, 5 de septiembre de 2000. Disponible en: http://www.lexivox. org/norms/BO-L-2115.xhtml

Brasil, Decreto 5.800, 8 de junho de 2006, dispõe sobre o Sistema Universidade Aberta do Brasil - UAB. Disponible en: https://www. planalto.gov.br/ccivil_03/_Ato2004-2006/2006/Decreto/D5800.htm

Brunner, J. J. (1990). Educación superior en América Latina: cambios y desafíos. Santiago de Chile: Facultad Latinoamericana de Ciencias Sociales, FLACSO.

Carnoy, M. (2007). Economía de la educación. Barcelona: Universitat Oberta de Catalunya, UOC.

Centro Interuniversitario de Desarrollo, CINDA (2010). Diagnóstico y diseño de intervenciones en equidad universitaria. Santiago, Centro Interuniversitario de Desarrollo, CINDA. Disponible en: https://www. academia.edu/4360023/Diagn\%C3\%B3stico_y_Dise\%C3\%B1o_de_ Intervenciones_en_Equidad_Universitaria 
Charfic, El Kfoûr, S. (2009). Descentralização e a gestão educacional. São Paulo: Expressão \& Alto Editora.

Chile, Decreto con Fuerza de Ley 4, Ley General de Universidades, fija normas sobre financiamiento de las universidades. Disponible en: http://www. leychile.cl/Navegar?idNorma=3621

Comité Ejecutivo de la Universidad Boliviana, CEUB (2014). Unidad de Información y Estadística Año III, No. 3, La Paz.

Debesa, F. (24 de noviembre de 2013). Impulsan más universidades $K$ y crece el debate por el descontrol. Clarín. Disponible en: http://www. clarin.com/sociedad/Impulsan-universidadescrece-debate-descontrol_0_1035496586.html

EABolivia, Diario Digital (s.f.). Universidad Pública de El Alto, UPEA. Disponible en: http://www.eabolivia. com/upea-universidad-publica-de-el-alto.html

Ecuador, Ley 298 Orgánica de Educación Superior, 12 de octubre de 2010. Disponible en: http:// planipolis.iiep.unesco.org/upload/Ecuador/ Ecuador_Ley_organica_educacion_superior.pdf

El Sol de San Luis (24 de octubre de 2014). Firman convenio de colaboración las Universidades Interculturales del país. Sesionó en San Luis Potosí la ANUI. El Sol de San Luis. Disponible en: http://www.oem.com.mx/elsoldesanluis/notas/ n3585656.htm

Estado Plurinacional de Bolivia, Ministerio de Educación (2010). Ley 070, de Educación Avelino Siñani-Elizardo Pérez, 20 de diciembre de 2010. Disponible en: http://www.oei.es/quipu/bolivia/ Leydla\%20.pdf

Ezcurra, A. M. (2011). Igualdad en educación superior. Un desafío mundial. Los Polvorines: Universidad Nacional de General Sarmiento, UNGS.

Finot, I. (2001). Descentralización en América Latina: teoría y práctica. Serie Gestión Pública No. 12. Santiago de Chile: Instituto Latinoamericano y del Caribe de Planificación Económica y Social, ILPES, Comisión Económica para América Latina y el Caribe, CEPAL. Disponible en: http://repositorio. cepal.org/bitstream/handle/11362/7261/ s01030319_es.pdf?sequence $=1$

García-Guadilla, C. (2004). Comercialización de la educación superior. Algunas reflexiones para el caso latinoamericano. Revista de la Educación Superior, 33 (2), 130, 65-74. Disponible en: http://publicaciones.anuies.mx/pdfs/revista/ Revista130_S2A4ES.pdf

Grupo de Iniciativas para la Calidad de la Educación Superior, GICES (2006). Informe sobre la regionalización de la educación universitaria en el Perú. Lima: Instituto Internacional de la UNESCO para la Educación Superior en América Latina y el Caribe, UNESCO-IESALC.

Grille, L. (2013). VII Censo Estudiantil de la Universidad de la República. Primera Generación. Caras y Caretas, 638, 8-14.

Hanushek, E. (2011). La importancia de la calidad en la educación. En Salvador Cardús, Walter Feinberg, Eric Yanushek, Blanca Heredia, José Antonio Marina, Sergio Rizzo, Isabella Schulte-Tenckhoff \& Gian Antonio Stella (2011). Los laberintos de la educación. Madrid: Gedisa.

Heredia, B. (2011). Educación para el desarrollo. En Salvador Cardús, Walter Feinberg, Eric Yanushek, Blanca Heredia, José Antonio Marina, Sergio Rizzo, Isabella Schulte-Tenckhoff \& Gian Antonio Stella (2011). Los laberintos de la educación. Madrid: Gedisa.

Herrera-Herrera, María Eugenia (2013). Identificación y relación de los principales elementos del proceso de regionalización de las instituciones de educación superior públicas en Colombia. Tesis de grado, Universidad Pontificia Bolivariana, Colombia.

Instituto Internacional de la UNESCO para la Educación Superior en América Latina y el Caribe, IESALC (2005). Feminización de la matrícula de la educación superior en América Latina y el Caribe. Rosaura Sierra \& Gisela Rodríguez (comps.). México: Unión de Universidades de América Latina y el Caribe, UDUAL, Instituto Internacional de la UNESCO para la Educación Superior en América Latina y el Caribe, UNESCO-IESALC.

La Hora Nacional (5 de julio de 2013). Nuevas universidades con visto bueno. La Hora Nacional. Disponible en: http://www.lahora.com.ec/index.php/noticias/ show/1101530815/-1/Nuevas_universidades_con_ visto_bueno.html\#.UdjFnDvcnw8

La Nación (30 de octubre de 2015). Eliminan el examen de ingreso para las universidades. La Nación. Disponible en: http://www.lanacion. com.ar/1841193-eliminan-el-examen-de-ingresopara-las-universidades

Martínez, F. (2002). La federalización de la educación superior en México. Alcances y limitaciones del proceso en la década de los noventa. México: Asociación Nacional de Universidades e Instituciones de Educación Superior, ANUIES.

Mato, D. (2015). Educación superior y pueblos indígenas en América Latina. Contextos y experiencias. Buenos Aires: Universidad Nacional de Tres de Febrero, UNTREF.

Ministerio de Educación y Cultura, MEC (2012). Datos sobre la educación superior en el Paraguay. Asunción, Paraguay: Viceministerio de Educación Superior. Disponible en: http://www.mec.gov. py/cms_v2/adjuntos/5717 
Moncayo, É. (2002). Nuevos enfoques teóricos, evolución de las políticas regionales e impacto territorial de la globalización. Serie Gestión Pública No. 27. Santiago de Chile: Instituto Latinoamericano y del Caribe de Planificación Económica y Social, ILPES, Comisión Económica para América Latina y el Caribe, CEPAL. Disponible en: http://repositorio.cepal.org/bitstream/handle/11362/7277/ S0212982_es.pdf? sequence $=1$

Montecinos, E (2013). Los actuales desafíos regionales en Chile: inueva regionalización o más descentralización? Los Lagos: Universidad de Los Lagos, Centro de Estudios del Desarrollo Regional y Local, CEDER. Disponible en: http://achm.cl/eventos/seminarios/ $\mathrm{html} /$ documentos/2013/XI_ASAMBLEA_DE_MUNICIPALIDADES/ CONGRESO/PPT10.pdf

Morles, V.; Álvarez-Bedoya, N. \& Medina-Rubio, E. (2003). La educación superior en Venezuela. Caracas: Instituto Internacional de la UNESCO para la Educación Superior en América Latina y el Caribe, UNESCO-IESALC. Disponible en: http://unesdoc.unesco.org/ images/0013/001315/131594s.pdf

Musto, C. (2012). Estado del arte en torno a la regionalización en el Uruguay. Montevideo, Uruguay: Universidad de la República, UdelaR, Unidad de Apoyo Académico, UNAPAC, Comisión Coordinadora del Interior, CCl. http://www.cci.edu.uy/sites/default/ files/Estado\%20del\%20arte\%20en\%20torno\%20a\%20la\%20 regionalizaci\%C3\%B3n\%20en\%20el\%20Uruguay.pdf

Opinion.com.bo (2 de agosto de 2014). Universidades indígenas gradúan a 121 nuevos profesionales. Opinion.com.bo. Disponible en: http:// www.opinion.com.bo/opinion/articulos/2014/0802/noticias. php?id $=134842$

Organización de las Naciones Unidas para la Educación, la Ciencia y la Cultura, UNESCO, Instituto de Estadística de la UNESCO, UNESCO/ UIS. Base de datos. Disponible en: http://www.uis.unesco.org/Pages/ default.aspx

Pedroza-Flórez, R.; Villalobos-Monroy, G.; Farfán-García, C. \& NavarreteSánchez, E. (2010). Políticas compensatorias para la educación superior en 10 países de América Latina. México: Unión de Universidades de América Latina y el Caribe, UDUAL, Universidad Autónoma del Estado de México, UAEMEX.

Perú (1996). Decreto 882, Ley de promoción de la inversión en la educación. Disponible en: http://www4.congreso.gob.pe/comisiones/1997/ educacion/leduca/cap1.htm

Perú, Asamblea Nacional de Rectores, ANR (2011). Datos estadísticos universitarios. Lima. Disponible en: http://censos.inei.gob.pe/cenaun/ redatam inei/doc/ESTADISTICA_UNIVERSITARIAS.pdf

Presse, P. \& Nonato, A. (coords.) (2014). Análise setorial do ensino superior privado. Foz de Iguaçu, Paraná, Brasil: Hoper Educação.

Prieto-Figueroa, L. (2009). De una educación de castas a una educación de masas. Caracas: Instituto Internacional de la UNESCO para la Educación Superior en América Latina y el Caribe, UNESCO-IESALC, Fondo Editorial del Instituto de Previsión y Asistencia Social del Personal del Ministerio de Educación, IPASME.

Putnam, R. (1993). The Prosperous Community. Social Capital and Public Life. The American Theory and the Social Capital Debate. American Prospect, 4 (13), 35-42. Disponible en: http://prospect.org/article/ prosperous-community-social-capital-and-public-life 
Rama, C. (2006). La tercera reforma de la educación superior en América Latina. Buenos Aires: Fondo de Cultura Económica, FCE.

Rama, C. (2009a). La tendencia a la masificación de la cobertura de la educación superior en América Latina. Revista Iberoamericana de Educación, 50, 173-195. http://www.rieoei.org/rie50a09.pdf

Rama, C. (2009b). La universidad latinoamericana en la encrucijada de sus tendencias. Santo Domingo, República Dominicana: Universidad del Caribe, UNICARIBE.

Rama, C. (2011). Paradigmas emergentes, competencias profesionales y nuevos modelos universitarios en América Latina. Puebla, México: Benemérita Universidad Autónoma de Puebla, Ediciones de Educación y Cultura.

Rama, C. (2012a). La nueva fase de la universidad privada en América Latina. Montevideo, Uruguay: Magro Editores, Universidad de la Empresa, UDE.

Rama, C. (2012b). La reforma de la virtualización de la universidad. El nacimiento de la educación digital. México: Universidad de Guadalajara. Disponible en: http://virtualeduca.org/documentos/observatorio/ libro_la-reforma-de-la-virtualizacion-de-la-universidad-claudio-ramaudg-2012.pdf

Rama, C. (2014). La dinámica pendular de la regionalización de la universidad en Argentina. Debate Universitario CAEE-UAI, 3 (5), 9-26. Disponible en: http://dialnet.unirioja.es/servlet/articulo?codigo $=4896311$

Rama, C. (2015a). La conformación diferenciada de un nuevo subsistema tecnológico universitario en América Latina. Revista de la Educación Superior, XLIV (1), 173, 11-46. Disponible en: http://publicaciones. anuies.mx/pdfs/revista/Revista173_S3A1ES.pdf

Rama, C. (2015b). Nuevas formas de regionalización de la educación superior en América Latina: la universidad red y los cluster universitarios. Revista Gestão Universitária na América Latina, GUAL, 8 (2), 302-328. Disponible en: https://periodicos.ufsc.br/index.php/ gual/article/viewFile/1983-4535.2015v8n2p302/29296

Rangel-Sostmann, R. (2014). Universidad 2.0. México: Taurus.

República Dominicana, Ley 5778 de autonomía de la UASD, 26 de octubre de 1961. Gaceta Oficial, 8633, 5 de enero de 1962, 31 de diciembre de 1961. Disponible en: https://bonoc.files.wordpress. com/2008/12/ley-5778.pdf

Rojas, R. (2005). Historia de la Universidad en Venezuela. Revista Historia de la Educación Latinoamericana, 7, 73-98. Disponible en: http:// dialnet.unirioja.es/servlet/articulo?codigo $=2334926$

Sampaio, H. (2014). O setor privado de ensino superior no Brasil: trajetória e perspectivas. En La educación superior pública y privada en América Latina. Contexto de internacionalización y proyecciones de políticas públicas, 155-192. Bogotá: Instituto Internacional de la UNESCO para la Educación Superior en América Latina y el Caribe, IESALC, Fundación Andina. Disponible en: http://www.iesalc.unesco.org.ve/ index.php?option $=$ com_fabrik\&view $=$ details\&formid $=2 \&$ rowid $=17$ 3\&lang $=\mathrm{es}$

San Segundo, J. M. (2001). Economía de la educación. Madrid: Síntesis Educación.

Sigal, V. \& Dávila, M. (2005). La educación superior no universitaria argentina. Buenos Aires: Universidad de Belgrado, Siglo XXI.

Síntesis Vox (s.f.). Crean Asociación Nacional de Universidades Interculturales. Trabajarán en conjunto para el fortalecimiento de la educación 
superior con enfoque intercultural en México. Síntesis Vox. Disponible en: http://sintesis.mx/vox/nota.php?id=9939\&plaza=chiapas

Solana, F. (comp.). Educación y desigualdad. México: Siglo XXI.

Taquini, A. (hijo). (2000). La transformación de la educación superior argentina: de las nuevas universidades a los colegios universitarios. Buenos Aires: Academia Nacional de Educación.

Torres, P. L; Vianney, J. \& Roesler, J. (2008). La educación a distancia en Brasil. En Patricia Lupion Torres \& Claudio Rama (coords.). La educación a distancia en América Latina y el Caribe: realidades y tendencias, 37-60. Tubarão, Santa Catarina, Brasil: Universidade do Sul de Santa Catarina, Editora Unisul. Disponible en: http://www. uned.es/catedraunesco-ead/cosypedal/Libro_EduDist2009.pdf

Tovar, H. (2005). Los institutos y colegios universitarios en el contexto de la educación superior venezolana. Caracas: Instituto Internacional de la UNESCO para la Educación Superior en América Latina y el Caribe, UNESCO-IESALC, Fondo Editorial del Instituto de Previsión y Asistencia Social del Personal del Ministerio de Educación, IPASME. Disponible en: http://www.fenasinpres.org.ve/documentos/iut_contexto.pdf

Vaca, M. (13 de abril de 2009). Bolivia: universidades solo para indígenas. BBC Mundo. Disponible en: http://www.bbc.co.uk/mundo/america_ latina/2009/04/090413_bolivia_universidades_indigenas_mr.shtml

Vélez-Álvarez, S. (2012). La regionalización en UNIMINUTOO. Sedes, centros regionales y CERES. Bogotá: Corporación Universitaria Minuto de Dios, UNIMINUTO. Disponible en: http://repository. uniminuto.edu:8080/xmlui/bitstream/handle/10656/1266/Libro_ SantiagoVelez_Regionalizacion_2012.pdf?sequence $=1$

Venezuela, Decreto 687, Ley de Universidades, 1 de septiembre de 1971. Disponible en: http://www.superior.consejos.usb.ve/sites/default/ files/Reglamento\%20Ley\%20de\%20Universidades\%201971.pdf

Venezuela, Ley de Universidades, 8 de septiembre de 1970. Disponible en: http://ucv.ve/fileadmin/user_upload/documentos/ley_de_ universidades.pdf

Verger-Planells, A. (2011). Regionalización de la educación superior y globalización económica: el caso del proceso de Bolonia. Revista de Innovación Educativa, 11 (56), 14-21.

Villa, L. (2001). Economía de la educación. Bogotá: Universidad de Los Andes. 